University of Wollongong

Research Online

Faculty of Engineering and Information

Faculty of Engineering and Information

Sciences - Papers: Part A

Sciences

$1-1-2016$

Evaluating ionic organic draw solutes in osmotic membrane bioreactors for water reuse

Wenhai Luo

University of Wollongong, w1344@uowmail.edu.au

Faisal I. Hai

University of Wollongong, faisal@uow.edu.au

William E. Price

University of Wollongong, wprice@uow.edu.au

Menachem Elimelech

Yale University

Long D. Nghiem

University of Wollongong, longn@uow.edu.au

Follow this and additional works at: https://ro.uow.edu.au/eispapers

Part of the Engineering Commons, and the Science and Technology Studies Commons

Research Online is the open access institutional repository for the University of Wollongong. For further information contact the UOW Library: research-pubs@uow.edu.au 


\title{
Evaluating ionic organic draw solutes in osmotic membrane bioreactors for water reuse
}

\begin{abstract}
The performance of two ionic organic draw solutes, namely sodium acetate $(\mathrm{NaOAc})$ and ethylenediamine-tetra acetic acid disodium salt (EDTA-2Na), during osmotic membrane bioreactor (OMBR) operation was investigated in this study. Their performance was compared to that of sodium chloride $(\mathrm{NaCl})$. A reverse osmosis (RO) process was integrated with OMBR to form an OMBR-RO hybrid system for draw solute recovery and clean water production. Results show that the NaOAc and EDTA-2Na draw solutes significantly reduced salinity build-up in the bioreactor in comparison with $\mathrm{NaCl}$ during OMBR operation. At the same osmotic pressure, these two ionic organic draw solutions produced slightly lower water flux, but considerably less reverse salt flux than $\mathrm{NaCl}$. Compared to $\mathrm{NaCl}$ and $\mathrm{NaOAc}$, EDTA-2Na resulted in significantly less fouling to the forward osmosis membrane. Regardless of the draw solutes, the OMBR-RO hybrid system could remove all 31 trace organic contaminants investigated in this study by more than $97 \%$. Results reported here suggest that ionic organic draw solutes can be used to mitigate salinity build-up in the bioreactor during OMBR operation.
\end{abstract}

\section{Keywords}

membrane, osmotic, solutes, draw, organic, ionic, evaluating, water, reuse, bioreactors

Disciplines

Engineering | Science and Technology Studies

\section{Publication Details}

Luo, W., Hai, F. I., Price, W. E., Elimelech, M. \& Nghiem, L. D. (2016). Evaluating ionic organic draw solutes in osmotic membrane bioreactors for water reuse. Journal of Membrane Science, 514 636-645. 


\section{Evaluating ionic organic draw solutes in osmotic membrane bioreactors for water reuse}

Revised manuscript submitted to Journal of Membrane Science

May 2016

Wenhai Luo a, Faisal I. Hai a , William E. Price ${ }^{b}$, Menachem Elimelech ${ }^{c}$, and Long D. Nghiem ${ }^{a^{*}}$

${ }^{\text {a }}$ Strategic Water Infrastructure Laboratory, School of Civil, Mining and Environmental Engineering, University of Wollongong, Wollongong, NSW 2522, Australia

${ }^{\mathrm{b}}$ Strategic Water Infrastructure Laboratory, School of Chemistry, University of Wollongong, Wollongong, NSW 2522, Australia

${ }^{\mathrm{c}}$ Department of Chemical and Environmental Engineering, Yale University, New Haven, Connecticut 06520-8286, United States

*Corresponding author: longn@uow.edu.au; Ph: +61 (2) 42214590. 


\begin{abstract}
The performance of two ionic organic draw solutes, namely sodium acetate (NaOAc) and ethylene-diamine-tetra acetic acid disodium salt (EDTA-2Na), during osmotic membrane bioreactor (OMBR) operation was investigated in this study. Their performance was compared to that of sodium chloride $(\mathrm{NaCl})$. A reverse osmosis $(\mathrm{RO})$ process was integrated with OMBR to form an OMBR-RO hybrid system for draw solute recovery and clean water production. Results show that the NaOAc and EDTA-2Na draw solutes significantly reduced salinity build-up in the bioreactor in comparison with $\mathrm{NaCl}$ during OMBR operation. At the same osmotic pressure, these two ionic organic draw solutions produced slightly lower water flux, but considerably less reverse salt flux than $\mathrm{NaCl}$. Compared to $\mathrm{NaCl}$ and $\mathrm{NaOAc}$, EDTA-2Na resulted in significantly less fouling to the forward osmosis membrane. Regardless of the draw solutes, the OMBR-RO hybrid system could remove all 31 trace organic contaminants investigated in this study by more than 97\%. Results reported here suggest that ionic organic draw solutes can be used to mitigate salinity build-up in the bioreactor during OMBR operation.
\end{abstract}

Keywords: Osmotic membrane bioreactor (OMBR); organic draw solute; salinity build-up; reverse osmosis (RO); trace organic contaminants (TrOCs) 


\section{Introduction}

Inadequate access to clean water is a pervasive problem currently afflicting billions of people globally [1]. Water scarcity is further exacerbated by climate change, urbanisation, population growth, and environmental pollution. In recent years, there have been many dedicated efforts to develop and improve treatment processes that utilize alternative water sources, such as municipal wastewater, to augment water supply and alleviate water scarcity.

Water reuse has been identified as an effective and pragmatic approach to simultaneously address water scarcity and environmental pollution. A major obstacle to water reuse is the unreliable and often low removal of trace organic contaminants (TrOCs) by conventional wastewater treatment processes [2]. TrOCs occur ubiquitously in municipal wastewater at trace concentrations (from a few $\mathrm{ng} / \mathrm{L}$ to several $\mu \mathrm{g} / \mathrm{L}$ ) that present a potential health risk to humans and other living organisms [3]. As a result, a typical indirect potable water reuse scheme requires a series of advanced treatment processes to further purify the secondary treated effluent from a conventional wastewater treatment plant. These treatment processes often include microfiltration (MF) or ultrafiltration (UF), reverse osmosis (RO), and ultraviolet (UV) disinfection or advanced oxidation [1, 4]. The operation of multiple treatment barriers is, however, inherently complex and expensive. Thus, a strategic focus of the water industry is to simplify operation and reduce treatment cost while maintaining a high treatment standard.

Recent research progress in wastewater treatment and reuse has led to the development of osmotic membrane bioreactor (OMBR) [5-8]. OMBR utilizes forward osmosis (FO) to extract treated water from a bioreactor mixed liquor into a highly concentrated draw solution. A subsequent separation process, such as RO or membrane distillation, is often used for draw solute recovery and clean water production [9]. By employing a selective, semi-permeable FO membrane, various emerging TrOCs can be effectively retained in the bioreactor for further biodegradation. Indeed, several studies have demonstrated the potential of OMBR for enhanced removal of TrOCs $[10,11]$. In addition, due to the use of osmotic pressure as the driving force, FO has a lower membrane fouling propensity than pressure-driven membrane processes (e.g. MF and UF) [12]. Although fouling does occur to the FO membrane, it is reversible in most cases [13].

Salinity build-up in the bioreactor is a key issue associated with OMBR due to the reverse draw solute flux and high salt rejection by the FO membrane. The elevated salinity in the 
bioreactor can reduce the effective driving force (i.e. transmembrane osmotic pressure) for water permeation, alter microbial community [14, 15], and increase soluble microbial products (SMP) and extracellular polymeric substance (EPS) in the mixed liquor, thereby deteriorating the biological treatment and aggravating membrane fouling [16]. Thus, several approaches have been proposed to address the challenge of salinity build-up during OMBR operation. These include regular sludge wastage and integrating an MF or UF process with OMBR to bleed out dissolved inorganic salts from the bioreactor $[11,17,18]$.

Another promising approach to control salinity build-up in OMBR operation is to use ionic organic draw solutes as organic salts that diffuse into the bioreactor can be biodegraded by activated sludge $[9,19,20]$. However, with very few exceptions, ionic organic draw solutes have only been evaluated in FO applications. Bowden et al. [19] investigated the performance (i.e. the water and reverse salt fluxes) of several ionic organic draw solutes in FO operation and proposed the potential of sodium and magnesium based organic draw solutes for OMBR applications. Ansari et al. [20] subsequently suggested the benefits of ionic organic draw solutes, particularly sodium acetate $(\mathrm{NaOAc})$, over their inorganic counterparts in anaerobic OMBR applications by evaluating their performance in FO operation to pre-concentrate municipal wastewater for subsequent anaerobic treatment. In a recent study, Nguyen et al. [8] observed a stable water flux and low salinity build-up in the bioreactor over 68 days when ethylene-diamine-tetra acetic acid disodium salt (EDTA-2Na) coupled with polyethylene glycol tert-octylphenyl ether (Triton X-100) was used as the draw solute for a novel OMBR, in which FO was integrated with a moving bed biofilm reactor (MBBR). Nevertheless, the performance of ionic organic draw solutes in OMBR applications with conventional activated sludge treatment is still mostly unknown.

This study aims to evaluate the performance of two ionic organic draw solutes, namely $\mathrm{NaOAc}$ and EDTA-2Na, in OMBR operation with activated sludge. Their performance was compared to that of a widely used sodium chloride $(\mathrm{NaCl})$ draw solute in terms of water flux, membrane fouling, and biological stability of OMBR. A cross-flow RO process was integrated with OMBR to form an OMBR-RO hybrid system for draw solute recovery and clean water production. TrOC removal by the hybrid system with each draw solute was also analysed. Results reported here provide important insights for managing salinity build-up in the bioreactor and determining suitable draw solutes for practical OMBR applications. 


\section{Materials and methods}

\subsection{Draw solutes}

$\mathrm{NaOAc}$ and EDTA-2Na were selected to represent ionic organic draw solutes widely used in recent FO applications. $\mathrm{NaOAc}$ is highly biodegradable and enables to produce competitive water flux, but considerably less reverse salt flux than $\mathrm{NaCl}$ during $\mathrm{FO}$ operation $[19,20]$. EDTA-2Na has been proposed as an alternative draw solute to $\mathrm{NaCl}$ due to its small reverse salt flux in FO applications for sludge dewatering [21] and wastewater pre-concentration [20].

In this study, the performance of these two ionic organic draw solutes was compared to that of $\mathrm{NaCl}$ at a solution osmotic pressure of 23 bar (approximately the osmotic pressure of seawater). Based on the simulation results obtained from the OLI Stream Analyser software (OLI Systems, Morris Plains, NJ), the three draw solutions were 0.6 M NaOAc, $0.3 \mathrm{M}$ EDTA-2Na, and $0.5 \mathrm{M} \mathrm{NaCl}$, respectively. To completely dissolve the solute, the EDTA-2Na draw solution $\mathrm{pH}$ was adjusted to $\mathrm{pH} 8$ using a concentrated $\mathrm{NaOH}$ solution. No $\mathrm{pH}$ adjustment was applied to the $\mathrm{NaOAc}$ and $\mathrm{NaCl}$ draw solutions, which had an intrinsic $\mathrm{pH}$ of approximately 8.5 and 7.5 , respectively.

\subsection{Synthetic wastewater and trace organic contaminants}

A synthetic wastewater, simulating medium strength municipal sewage, was used to feed the OMBR. The synthetic wastewater was prepared daily and contained $100 \mathrm{mg} / \mathrm{L}$ glucose, 100 $\mathrm{mg} / \mathrm{L}$ peptone, $17.5 \mathrm{mg} / \mathrm{L} \quad \mathrm{KH}_{2} \mathrm{PO}_{4}, 17.5 \mathrm{mg} / \mathrm{L} \quad \mathrm{MgSO}_{4}, 10 \mathrm{mg} / \mathrm{L} \quad \mathrm{FeSO}_{4}, 225 \mathrm{mg} / \mathrm{L}$ $\mathrm{CH}_{3} \mathrm{COONa}$, and $35 \mathrm{mg} / \mathrm{L}$ urea [22].

A stock solution containing $25 \mu \mathrm{g} / \mathrm{mL}$ of each of the 31 TrOCs was prepared in pure methanol and stored at $-18{ }^{\circ} \mathrm{C}$ in the dark. The stock solution was introduced into the synthetic wastewater to obtain a concentration of $5 \mu \mathrm{g} / \mathrm{L}$ of each compound in each draw solute experiment. The TrOC stock solution was used within a month. These TrOCs were selected to represent four major groups of emerging contaminants of significant concern endocrine disrupting compounds, pharmaceutical and personal care products, industrial chemicals, and pesticides - that occur ubiquitously in municipal wastewater. Key physicochemical properties of these TrOCs are summarized in Table S1 of the Supplementary Data. Based on their effective octanol-water partition coefficient (Log D) at 
solution $\mathrm{pH} 8$, the 31 TrOCs investigated here could be classified as hydrophobic (i.e. Log D $>3.2$ ) and hydrophilic (i.e. $\log \mathrm{D}<3.2)$ [23].

\subsection{Osmotic membrane bioreactor - reverse osmosis system}

A bench-scale OMBR-RO hybrid system was used in this study (Figure 1). The hybrid system was consisted of a feed reservoir, an aerobic bioreactor, a submerged FO component, a draw solution reservoir and a cross-flow RO unit. The RO process was integrated with OMBR for draw solute recovery and clean water production. It is noteworthy that the additional RO process can increase the capital cost and energy consumption of the hybrid system, compromising the benefits of OMBR over conventional MBR systems. Thus, efficient and cost-effective processes should be developed for draw solute and clean water recovery in practical OMBR applications. This issue, however, is beyond the scope of current study.

A Masterflex peristaltic pump (Cole-Parmer, Vernon Hills, IL) controlled by a water level sensor was used to feed the bioreactor. The feed tank was placed on a digital balance (Mettler-Toledo, Hightstown, IL) connected to a computer to determine the OMBR water flux. A plate-and-frame FO membrane cell made of acrylic plastic was submerged in the bioreactor. A flat-sheet, cellulose triacetate FO membrane from Hydration Technology Innovations (HTI, Albany, OR) was mounted on the cell to seal the draw solution flow channel with a length, width, and height of 20,15 , and $0.4 \mathrm{~cm}$, respectively. The membrane active layer was in contact with activated sludge (i.e. FO mode) with an effective surface area of $300 \mathrm{~cm}^{2}$. A gear pump (Micropump, Vancouver, WA) was used to circulate the draw solution from a stainless steel reservoir to the membrane cell at a cross-flow velocity of 2.8 $\mathrm{cm} / \mathrm{s}$.

\section{[FIGURE 1]}

The RO component was composed of a Hydra-Cell pump (Wanner Engineering, Minneapolis, MN) and a stainless steel, cross-flow membrane cell. An ESPA2 RO membrane (Hydranautics, Oceanside, CA) was embedded into the membrane cell, which had a flow channel height of $0.2 \mathrm{~cm}$ and an effective membrane surface area of $40 \mathrm{~cm}^{2}(4 \mathrm{~cm} \times 10 \mathrm{~cm})$. The applied hydraulic pressure and cross-flow velocity were regulated by a back-pressure regulator (Swagelok, Solon, $\mathrm{OH}$ ) and a bypass valve. A temperature controller unit (Neslab RTE7, Waltham, MA) equipped with a stainless steel heat exchanger coil was used to maintain the feed solution (i.e. OMBR draw solution) temperature of $22 \pm 1{ }^{\circ} \mathrm{C}$. The 
permeate flux was monitored by a digital flow meter (Optiflow, Palo Alto, CA) connected to a computer. Further details of this RO component are available elsewhere [22].

\subsection{Experimental protocol}

Activated sludge from the Wollongong Wastewater Treatment Plant (Wollongong, Australia) was used to inoculate the bioreactor. The bioreactor was acclimatized to the synthetic wastewater mentioned above for over 40 days using a submerged, hollow fibre MF membrane module (Mitsubishi Rayon Engineering, Tokyo, Japan) to extract the treated water. Once acclimatized in terms of bulk organic removal (i.e. over 97\% total organic carbon (TOC) removal), the activated sludge was centrifuged at $2167 \mathrm{~g}$ for $5 \mathrm{~min}$ and reconstituted with the synthetic wastewater to adjust the mixed liquor suspended solids (MLSS) concentration to $5 \mathrm{~g} / \mathrm{L}$. The MF membrane was then removed and the bioreactor was integrated with the FO and RO components to form the OMBR-RO hybrid system (Figure 1). OMBR-RO experiments were separately conducted using an individual draw solution (i.e. 0.5 $\mathrm{M} \mathrm{NaCl}, 0.6 \mathrm{M} \mathrm{NaOAc}$, or 0.3 M EDTA-2Na). The working volumes of the bioreactor and draw solution reservoir were 6 and $10 \mathrm{~L}$, respectively. The bioreactor was continuously aerated to maintain the mixed liquor dissolved oxygen (DO) concentration of $5 \mathrm{mg} / \mathrm{L}$. In practice, salinity build-up in the bioreactor can be alleviated to some extent by regular sludge wastage. In this study, no sludge was wasted (except for weekly sampling of $120 \mathrm{~mL}$ mixed liquor) to systematically investigate salinity build-up in the bioreactor. The initial hydraulic retention time (HRT) was determined by the initial FO water flux with each draw solution and was in the range of $33-43$ hours. The permeate flux of the RO membrane was adjusted daily to match that of the FO membrane by changing the applied hydraulic pressure while maintaining the cross-flow velocity at $41.7 \mathrm{~cm} / \mathrm{s}$. Each OMBR-RO experiment was continuously run for 30 days in a temperature-controlled room $\left(22 \pm 1{ }^{\circ} \mathrm{C}\right)$. Membrane cleaning was conducted by removing the membrane module from the bioreactor and physically flushing the membrane surface with deionized water on day 10 and 20. Prior to each OMBR-RO experiment, the reverse salt flux of each draw solution was measured in duplicate with deionized water as the feed solution following a standard method reported by Cath et al. [24].

\subsection{Analytical methods}




\subsubsection{Water quality parameters}

TrOC concentrations in aqueous samples collected weekly from the feed, mixed liquor supernatant, draw solution, and RO permeate were analysed based on a method described by Hai et al. [25]. Briefly, this method involved solid phase extraction, derivatisation, and quantification by a gas chromatography-mass spectrometry (GC-MS) system (QP5000, Shimadzu, Kyoto).

TrOC removals by the bioreactor $\left(R_{B i o}\right)$, OMBR $\left(R_{O M B R}\right)$, and OMBR-RO hybrid system $\left(R_{\text {Overall }}\right)$ are defined as follows:

$$
\begin{aligned}
& R_{\text {Bio }}=\left(1-\frac{C_{\text {Sup }} V_{\text {Bio }}+C^{*}{ }_{\text {Draw }} \Delta V}{C_{\text {Feed }} \cdot \Delta V}\right) \times 100 \% \\
& R_{\text {OMBR }}=\left(1-\frac{C_{\text {Draw }}^{*}}{C_{\text {Feed }}}\right) \times 100 \% \\
& R_{\text {Overall }}=\left(1-\frac{C_{\text {Permeate }}}{C_{\text {Feed }}}\right) \times 100 \%
\end{aligned}
$$

where $C_{F e e d}, C_{S u p}$, and $C_{\text {Permeate }}$ are the measured TrOC concentrations (ng/L) in the feed, mixed liquor supernatant, and RO permeate, respectively; $C^{*}{ }_{\text {Draw }}$ is the TrOC concentrations in the FO permeate; $V_{B i o}$ is the effective bioreactor volume (i.e. $6 \mathrm{~L}$ ); and $\Delta V$ is the permeate volume passed through the FO membrane between time $t$ and $t+\Delta t$. It is noteworthy that TrOCs that permeated through the FO but not the RO membrane can accumulate in the draw solution [26]. Thus, $C^{*}$ Draw is determined from the mass balance:

$$
\begin{aligned}
& C_{\text {Draw }}^{*}=\frac{M_{F O}}{Q_{F O}} \\
& M_{F O}=\frac{V_{\text {Draw }}\left(C_{\operatorname{Draw}(t+\Delta t)}-C_{\operatorname{Draw}(t)}\right)}{\Delta t}+\frac{M^{*}{ }_{R O}}{\Delta t} \\
& M^{*}{ }_{R O}=\frac{\left(C_{R O(t+\Delta t)}+C_{R O(t)}\right)}{2} \Delta V \\
& \Delta V=Q_{R O} \Delta t
\end{aligned}
$$

where $M_{F O}$ is the mass flow rate of TrOCs crossed through the FO membrane; $M_{R O}^{*}$ is the mass of TrOCs permeated through the RO membrane between time $t$ and $t+\Delta t$; and $Q_{F O}$ and $Q_{R O}$ are the permeate fluxes of the FO and RO membranes, respectively. These two permeate 
fluxes were consistent to maintain the draw solution working volume $\left(V_{\text {Draw }}\right)$ of $10 \mathrm{~L}$ throughout each experiment (Section 2.4). $C_{\operatorname{Draw}(t)}, C_{\operatorname{Draw}(t+\Delta t)}, C_{R O(t)}$, and $C_{R O(t+\Delta t)}$ are the measured TrOC concentrations in the draw solution and RO permeate at time $t$ and $t+\Delta t$, respectively. Based on eqs. (4) - (7), $C_{\text {Draw }}^{*}$ is calculated as:

$$
C_{\text {Draw }}^{*}=\frac{V_{\text {Draw }}\left(C_{\operatorname{Draw}(t+\Delta t)}-C_{\operatorname{Draw}(t)}\right)}{\Delta V}+\frac{\left(C_{R O(t+\Delta t)}+C_{R O(t)}\right)}{2}
$$

According to eqs. (1) - (3), the observed TrOC rejection by the FO $\left(R_{O b F O}\right)$ and $\mathrm{RO}\left(R_{O b} R O\right)$ membranes is calculated as follows:

$$
\begin{aligned}
& R_{O b F O}=R_{O M B R}-R_{B i o} \\
& R_{O b R O}=R_{\text {Overall }}-R_{O M B R}
\end{aligned}
$$

It is noteworthy that the observed TrOC rejection rates can not reflect the actual separation capacity of the FO and RO membranes, but can be used to infer their roles in the OMBR-RO hybrid system for TrOC removal.

Basic water quality of aqueous samples was also evaluated. TOC and total nitrogen (TN)

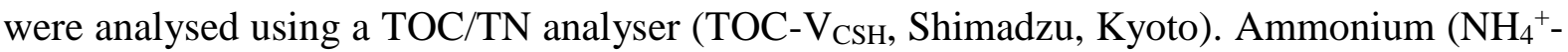
$\mathrm{N})$ and orthophosphate $\left(\mathrm{PO}_{4}{ }^{3-}-\mathrm{P}\right)$ were determined by a Flow Injection Analysis system (QuikChem 8500, Lachat, CO). Solution $\mathrm{pH}$ and conductivity were monitored using an Orion 4-Star Plus pH/conductivity meter (Thermo Scientific, Waltham, MA).

\subsubsection{Biomass characterisation}

MLSS and mixed liquor volatile suspended solid (MLVSS) concentrations in the bioreactor were monitored following the Standard Method 2540. Biomass activity was evaluated by testing the specific oxygen uptake rate (SOUR) of activated sludge based on the Standard Method 1683. EPS in the sludge were extracted using a thermal method reported by Zhang et al. [27]. EPS and SMP in the mixed liquor were quantified by measuring protein and polysaccharide concentrations. Protein concentration was determined by the Folin method with bovine serum albumin as the standard [28]. Polysaccharide concentration was measured using the phenol-sulfuric acid method with glucose as the standard [29].

\section{Results and discussion}

\subsection{Salinity build-up in the bioreactor}


Salinity build-up in the bioreactor is an intrinsic phenomenon associated with OMBR due to the high salt rejection by the FO membrane and the reverse draw solute flux. Compared to $\mathrm{NaCl}$, both $\mathrm{NaOAc}$ and EDTA-2Na draw solutes resulted in significantly less salinity buildup in the bioreactor as manifested by the mixed liquor electrical conductivity profiles (Figure 2). This observation can be attributed in part to the lower water flux produced by these two ionic organic draw solutes in comparison with $\mathrm{NaCl}$ (Figure 3), thereby prolonging the operating HRT and leading to less salt concentration in the bioreactor. More importantly, compared to $\mathrm{NaCl}$, these two ionic organic draw solutes exhibited much lower reverse salt fluxes given their large molecular weight and thus small diffusion coefficient (Table 1). In addition, the significantly low reverse salt flux observed for EDTA-2Na could also be ascribed to its negatively charged ions, such as $\mathrm{H}[\mathrm{EDTA}]^{3-}$ at solution $\mathrm{pH} 8$, which could result in electrostatic repulsion between the solute and the negatively charged FO membrane $[8,21]$. Although the reverse salt flux of NaOAc was nearly twelve times higher than that of EDTA-2Na (Table 1), they contributed to almost identical mixed liquor increment (Figure 2), possibly due to the readily biodegradable nature of acetate $[19,30]$. Slightly higher mixed liquor conductivity was only observed with $\mathrm{NaOAc}$ at the end of the OMBR operation.

\section{[TABLE 1]}

\section{[FIGURE 2]}

\section{[FIGURE 3]}

In this study, the mixed liquor electrical conductivity increased from approximately 0.4 to 6.0 $\mathrm{mS} / \mathrm{cm}$ during OMBR operation with the $0.3 \mathrm{M}$ EDTA-2Na draw solution (Figure 2). A lower increase in the mixed liquor conductivity (only from approximately 0.3 to $0.6 \mathrm{mS} / \mathrm{cm}$ over 68 days) was observed by Nguyen et al. [8] who used a 0.8 M EDTA-2Na coupled with 1 M Triton X-100 (an non-ionic surfactant) draw solution for an MBBR-OMBR system. Such low salinity build-up in their study could be attributed to the presence of Triton X-100 in the draw solution, whose adsorption onto the FO membrane surface due to could narrow the membrane pores, thereby reducing the reverse permeation of EDTA-2Na [8].

\subsection{Water flux}

$\mathrm{NaCl}$ produced the highest initial water flux, closely followed by $\mathrm{NaOAc}$ and then EDTA$2 \mathrm{Na}$ at the same osmotic pressure of 23 bar (Figure 3). This result is consistent with a previous study by Ansari et al. [20] and could be attributed to the different diffusion coefficient of these draw solutes (Table 1). It has been reported that the draw solute with 
small diffusion coefficient could result in severe internal concentration polarisation (ICP) within the membrane supporting layer and thus lower the water flux in FO applications [20, $31]$.

Considerable flux decline was observed at the beginning of all three draw solute experiments (Figure 3). Given the high salt rejection by the RO membrane ( $>98 \%)$, only a small decrease in the draw solution concentrations was observed (Figure S1, Supplementary Data). Therefore, the observed flux decline was mainly caused by membrane fouling and salinity build-up in the bioreactor. In this case, membrane fouling appeared to play a significant role. As discussed in Section 3.1, due to the lower reverse salt flux (Table 1), NaOAc resulted in less salinity build-up in the bioreactor than $\mathrm{NaCl}$. However, the flux decline was more obvious for NaOAc (Figure 3), since its reverse salt flux could provide carbon sources for microbial growth and thus induce severe membrane fouling. Indeed, a thick biofilm layer was visualized on the membrane surface during OMBR operation with NaOAc (Figure S2, Supplementary Data), which comprised much higher polysaccharide- and protein-like substances than the fouling layer formed on the membrane surface with $\mathrm{NaCl}$ and EDTA2Na, respectively (Table S2, Supplementary Data).

FO membrane fouling was highly reversible and could be effectively controlled by physical flushing with deionized water in all three draw solute experiments. Compared to $\mathrm{NaOAc}$ and $\mathrm{NaCl}$, smaller flux decline was observed for EDTA-2Na and its water flux was maintained in the range of $3.5-4.5 \mathrm{~L} / \mathrm{m}^{2} \mathrm{~h}$ with periodic membrane flushing (Figure 3 ). The less membrane fouling occurred with EDTA-2Na can be partially attributed to its lower initial water flux. More importantly, EDTA is an anti-microbial chelating agent and its reverse transport could reduce membrane fouling by inhibiting microbial growth and limiting the intermolecular bridging among foulants on the membrane surface $[32,33]$. As a result, despite the formation of observable fouling layer on the membrane surface (Figure S2, Supplementary Data), it was easily removed by physical deionized water flushing. Nevertheless, the reverse flux of EDTA could undesirably affect bacterial growth and activity in the bulk activated sludge as discussed in the next section.

\subsection{Mixed liquor characteristics}

\subsubsection{Mixed liquor $\mathrm{pH}$}

Reverse draw solute flux increased the mixed liquor $\mathrm{pH}$ during OMBR operation (Figure 4). The mixed liquor $\mathrm{pH}$ increased to $\mathrm{pH} 8$ within the first 10 days when $\mathrm{NaCl}$ was used as the 
draw solute. This increase was driven by the forward diffusion of protons from the mixed liquor into the draw solution associated with the reverse transport of sodium cations to maintain the electroneutrality of the mixed liquor [34]. With the decrease in the water and reverse salt fluxes (Figure 2), no significant $\mathrm{pH}$ increase was observed thereafter.

\section{[FIGURE 4]}

As an alkaline salt, $\mathrm{NaOAc}$ resulted in a notable increase in the mixed liquor $\mathrm{pH}$ (Figure 4). To avoid negative effects of high $\mathrm{pH}$ on microbial viability and membrane performance, certain amount of concentrated $\mathrm{HCl}$ solution was added to adjust the mixed liquor $\mathrm{pH}$ to 7 once it increased to $\mathrm{pH}$ 9. No $\mathrm{pH}$ adjustment to the mixed liquor was applied with the $\mathrm{NaCl}$ or EDTA-2Na draw solute. While the EDTA-2Na draw solution $\mathrm{pH}$ was adjusted to $\mathrm{pH} 8$ to completely dissolve the solute (Section 2.1), only a small increase in the mixed liquor pH was observed due to its low reverse salt flux (Table 1).

\subsubsection{Biomass characteristics}

Reverse draw solute flux significantly altered biomass characteristics (Figure 5). Although no excess sludge was wasted, a small but discernible decrease in biomass concentration (i.e. MLSS and, particularly MLVSS) was observed during OMBR operation with $\mathrm{NaCl}$ (Figure $5 \mathrm{a}$ and b). Moreover, sludge SOUR decreased, especially within the first two weeks of operation (Figure 5c). These observations are consistent with previous studies $[35,36]$ and could be attributed to the inhibition of elevated bioreactor salinity on biomass growth and activity. An increase in the osmotic stress could result in the dehydration and plasmolysis of bacterial cells and thus reduce their viability [37]. On the other hand, microbial response to the saline condition resulted in more SMP and EPS in the mixed liquor (Figure $5 \mathrm{~d}$ and e), which could exacerbate the reversible fouling of the FO membrane.

Biomass concentration and activity (indicated by sludge SOUR) increased during OMBR operation with $\mathrm{NaOAc}$ (Figure 5a-c), since reverse acetate flux could provide carbon sources for bacterial metabolism and growth. Ansari et al. [20] also observed the beneficial effects of reverse $\mathrm{NaOAc}$ flux on anaerobic treatment in comparison with its inorganic counterparts by evaluating methane production. Enhanced biomass activity may increase the biodegradation of SMP, particularly those produced via the erosion or hydrolysis of bacterial EPS [38]. As a result, the SMP concentration in the mixed liquor decreased continuously in OMBR operation with NaOAc (Figure 5d). No significant variation in the EPS concentration was 
observed, likely due to a balance between its release and hydrolysis (and/or erosion) (Figure $5 e)$.

EDTA can act as an anti-microbial chelating agent. Thus, the EDTA-2Na draw solute resulted in less membrane fouling during OMBR operation compared to other two draw solutes as discussed in Section 3.2. However, further investigation is required to elucidate impacts of reverse EDTA-2Na flux on bacterial growth and activity in OMBR applications. In this study, the sludge concentration and SOUR decreased significantly when EDTA-2Na was employed as the draw solute (Figure 5a-c). Negative effects of EDTA on activated sludge was also reported by Diez et al. [39] who attributed those to the release of multivalent ions, such as calcium, from the cell membrane structure with the presence of EDTA, thereby deflocculating sludge flocs and inhibiting microbial viability. Moreover, the elevated EDTA concentration in the bioreactor could increase the secretion and hydrolysis of organic cellular substances, especially lipopolysaccharide- and humic-like matters [40, 41]. As a result, both SMP and EPS concentrations in the mixed liquor increased significantly in OMBR operation with EDTA-2Na (Figure 5d and e).

\subsection{Removal of bulk organic matter and nutrients}

The synergy between the activated sludge treatment and the dual high-retention membrane barriers (i.e. FO and RO) secured the high contaminant removal by the OMBR-RO hybrid system, regardless of the draw solutes (Figures 6 and 7). Nevertheless, the reverse draw solute flux undesirably impacted the biological treatment of OMBR. TOC concentration in the bioreactor increased slightly at the beginning of OMBR operation with $\mathrm{NaCl}$ (Figure 6a). This observation is in agreement with that reported previously and could be attributed to the inhibitions on microbial activity caused by the elevated bioreactor salinity as well as the rejection of biologically persistent organics by the FO membrane [5, 14]. With microbial acclimatization to saline conditions [15], TOC concentration in the bioreactor decreased gradually and then stabilized at approximately $20 \mathrm{mg} / \mathrm{L}$ from day 10 onward.

Although the two ionic organic draw solutes could mitigate salinity build-up in the bioreactor (Figure 2), their reverse salt flux increased TOC concentration in the bioreactor (Figure $6 \mathrm{~b}$ and c). Compared to NaOAc, EDTA-2Na exhibited considerably less reverse salt flux (Table 1), but resulted in much more TOC in the bioreactor. This result could be ascribed to the high organic content of EDTA-2Na and its resistance against the activated sludge treatment [42]. It is noteworthy that TOC concentration in recycled water (i.e. RO permeate) was higher than 
$10 \mathrm{mg} / \mathrm{L}$ for these two ionic organic draw solutes because of the concentrated nature of the draw solution. Therefore, more effective processes should be employed for draw solute recovery and clean water production in OMBR applications with these ionic organic draw solutes.

In the aerobic bioreactor, TN consumption occurs mainly through microbial assimilation. At the same time, nitrification converts $\mathrm{NH}_{4}{ }^{+}-\mathrm{N}$ to nitrite $\left(\mathrm{NO}_{2}^{-}-\mathrm{N}\right)$ and then nitrate $\left(\mathrm{NO}_{3}{ }^{-}-\mathrm{N}\right)$ under aerobic conditions. These nitrogen species can be rejected to some extent by the FO membrane $[43,44]$. As a result, considerable TN build-up in the bioreactor was observed in OMBR operation with all three draw solutes (Figure 6d-f). Compared to $\mathrm{NaCl}, \mathrm{NaOAc}$ resulted in considerably less $\mathrm{TN}$ in the bioreactor, possibly due to the enhanced sludge activity associated with the reverse acetate flux as discussed in Section 3.3.2. Of the three draw solutes here, EDTA-2Na led to significantly more TN in the bioreactor as it is highly resistant to activated sludge treatment [42].

Incomplete nitrification is usually manifested by the detection of both $\mathrm{NH}_{4}{ }^{+}-\mathrm{N}$ and $\mathrm{NO}_{\mathrm{x}}^{-}-\mathrm{N}$ in the bioreactor. An initial increase but subsequent decrease in bioreactor $\mathrm{NH}_{4}{ }^{+}-\mathrm{N}$ concentration was observed in OMBR operation with $\mathrm{NaCl}$ (Figure 7a). The observed $\mathrm{NH}_{4}{ }^{+}-$ $\mathrm{N}$ increase was likely caused by the inhibitory effects of high bioreactor salinity on nitrifiers, which are well-known bacteria for nitrification and susceptible to saline stress [45]. Nevertheless, nitrifiers in activated sludge could adapt to highly saline conditions (up to 30 $\mathrm{g} / \mathrm{L} \mathrm{NaCl}$ ) after acclimatization and thereby recover the nitrification capacity [46].

$\mathrm{NaOAc}$ could mitigate salinity build-up in the bioreactor and enhance microbial activity as discussed above. Thus, $\mathrm{NH}_{4}{ }^{+}-\mathrm{N}$ concentration in the mixed liquor was negligible in OMBR operation with $\mathrm{NaOAc}$, particularly from day 10 onward (Figure 7b). By contrast, EDTA$2 \mathrm{Na}$ caused a notable increase in the bioreactor $\mathrm{NH}_{4}{ }^{+}-\mathrm{N}$ concentration within the first 10 days (Figure 7c), since EDTA could inhibit the nitrification process [47]. No further increase was observed thereafter, possibly due to microbial adaptation to EDTA and the permeation of $\mathrm{NH}_{4}{ }^{+}-\mathrm{N}$ through the $\mathrm{FO}$ membrane into the draw solution (Figure 7c).

Phosphorus removal by activated sludge is largely determined by microbial assimilation, particularly by polyphosphate accumulating organisms [48]. These organisms are vulnerable to saline conditions. A small osmotic pressure increase within their cells due to salt accumulation may severely diminish their phosphate accumulating capacity [37]. Thus, phosphorus removal in OMBR occurs mainly by FO rejection [49]. Holloway et al. [43] have 
reported near complete rejection of phosphate by the FO membrane during concentration of anaerobic digester centrate, since phosphate ions are negatively charged and have large hydrated radius. In this study, $\mathrm{PO}_{4}{ }^{3-}-\mathrm{P}$ concentration in the bioreactor increased significantly in OMBR operation with all three draw solutes (Figure 7d-f). Compared to other two draw solutes, EDTA-2Na resulted in more remarkable $\mathrm{PO}_{4}{ }^{3-}-\mathrm{P}$ increase in the bioreactor. As a chelating agent, EDTA reversely transported to the bioreactor could dissolve phosphorus precipitates and therefore increase soluble phosphate ions.

Build-up of bulk organic matter (indicated by TOC and TN) and nutrients (i.e. $\mathrm{NH}_{4}{ }^{+}-\mathrm{N}$ and $\mathrm{PO}_{4}{ }^{3-}-\mathrm{P}$ ) in the draw solution was observed in all three OMBR-RO experiments (Figures 6 and 7). Similar results have also been reported in recent studies, where closed-loop OMBRRO and FO-RO hybrid systems were continuously operated [26, 50, 51]. This build-up phenomenon was driven by the higher contaminant rejection capacity of the RO than the FO membrane $[26,50]$. On the other hand, the build-up of contaminants in the bioreactor due to the negative effects of reverse draw solute flux on biological treatment could increase their permeation through the FO membrane. For example, nitrification inhibition by EDTA resulted in high $\mathrm{NH}_{4}{ }^{+}-\mathrm{N}$ concentration in the bioreactor and subsequently its notable accumulation in the EDTA-2Na draw solution (Figure 7c). Thus, an additional process, such as granular activated carbon adsorption, UV oxidation [52], or ion exchange [50] should be implemented to address contaminant accumulation in the draw solution for securing the high product water quality and sustainable operation of OMBR-RO or other closed-loop OMBR hybrid systems.

\subsection{Removal of trace organic contaminants}

Regardless of the draw solutes, the OMBR-RO hybrid system could remove all 31 TrOCs investigated here by over 97\% (Figure 8), given the synergy between the activated sludge treatment and membrane rejection. In the three draw solute experiments, all 12 hydrophobic TrOCs (with Log D > 3.2) were effectively removed from the bioreactor. It has been reported that hydrophobic TrOCs could be easily removed in activated sludge treatment due to their high adsorption onto biomass for subsequent biodegradation [23]. In addition, activated sludge could also highly remove several hydrophilic TrOCs (with Log $\mathrm{D}<3.2$ ), such as salicylic acid, naproxen, ibuprofen, formononetin, and DEET. These compounds are readily biodegradable, because their molecular structures possess strong electron donating functional groups, such as amine and hydroxyl $[23,53]$. As a result, the observed rejection of these 
compounds by both the FO and RO membranes was insignificant (Figure 8), suggesting that the removal of hydrophobic and readily biodegradable hydrophilic TrOCs in the OMBR-RO hybrid system mainly occurs through the activated sludge treatment.

Some hydrophilic TrOCs were poorly removed from the bioreactor in all three draw solute experiments (Figure 8). These included clofibric acid, fenoprop, diclofenac, carbamazepine, and atrazine, which are well-known biologically resistant compounds. Their resistance to biological treatment resulted from the presence of strong electron withdrawing functional groups (e.g. chloride, amide, and nitro) and/or the absence of strong electron donating functional groups in their molecular structures [23, 53]. Nevertheless, the dual barriers against small solutes created by the FO and RO membranes secured the high overall removal of these hydrophilic and biologically resistant TrOCs.

No significant difference in TrOC removal by the OMBR-RO hybrid system was observed for the three draw solutes (Figure 8). However, EDTA-2Na resulted in a slightly lower bioreactor removal of four nitrogen-bearing TrOCs, including propoxur, ametryn, atrazine and octocrylene, probably due to its inhibitory effects on nitrifiers as discussed Section 3.4. Wijekoon et al.[53] also reported that nitrifiers could biodegrade nitrogen-bearing TrOCs, particularly the compounds with nitrogen molecule in the cyclic structure.

\section{Conclusion}

Results reported here show that the NaOAc and EDTA-2Na draw solutes could mitigate salinity build-up in the bioreactor in comparison with $\mathrm{NaCl}$ during OMBR operation. At the same osmotic pressure, these two ionic organic draw solutions contributed slightly lower water flux, but considerably less reverse salt flux than $\mathrm{NaCl}$. Reverse salt flux of EDTA-2Na was less than one tenth of that of $\mathrm{NaOAc}$, which in turn was only half of that of $\mathrm{NaCl}$. Nevertheless, the salinity build-up profiles were almost identical for NaOAc and EDTA-2Na, since acetate was readily biodegradable. Moreover, DTA-2Na resulted in significantly less FO membrane fouling, followed by $\mathrm{NaCl}$ and $\mathrm{NaOAc}$, respectively. Regardless of the draw solutes, OMBR-RO could remove all 31 TrOC investigated here by over 97\%. These results suggest that ionic organic draw solutes can be potentially used for FO, rendering it compatible to biological treatment. Nevertheless, further investigation to evaluate any negative impact of ionic organic draw solutes on long-term performance of the biological process and the membrane is recommended. 


\section{Acknowledgment}

This research was supported under Australian Research Council's Discovery Project funding scheme (project DP140103864). Wenhai Luo would like to thank the Chinese Scholarship Council and the University of Wollongong for PhD scholarship support. Galilee Semblante is thanked for her assistance with FIA measurement.

\section{References}

[1] M.A. Shannon, P.W. Bohn, M. Elimelech. Science and technology for water purification in the coming decades, Nature 452 (2008) 301-310.

[2] R.P. Schwarzenbach, B.I. Escher, K. Fenner, T.B. Hofstetter, C.A. Johnson, U. von Gunten, B. Wehrli. The challenge of micropollutants in aquatic systems, Science 313 (2006) 1072-1077.

[3] Y.L. Luo, W.S. Guo, H.H. Ngo, L.D. Nghiem, F.I. Hai, J. Zhang, S. Liang, X.C.C. Wang. A review on the occurrence of micropollutants in the aquatic environment and their fate and removal during wastewater treatment, Sci. Total Environ. 473 (2014) 619-641.

[4] T. Fujioka, S.J. Khan, Y. Poussade, J.E. Drewes, L.D. Nghiem. N-nitrosamine removal by reverse osmosis for indirect potable water reuse - A critical review based on observations from laboratory-, pilot- and full-scale studies, Sep. Purif. Technol. 98 (2012) 503-515.

[5] A. Achilli, T.Y. Cath, E.A. Marchand, A.E. Childress. The forward osmosis membrane bioreactor: A low fouling alternative to MBR processes, Desalination 239 (2009) 10-21.

[6] E.R. Cornelissen, D. Harmsen, E.F. Beerendonk, J.J. Qin, H. Oo, K.F. De Korte, J.W.M.N. Kappelhof. The innovative osmotic membrane bioreactor (OMBR) for reuse of wastewater, Water Sci. Technol. 63 (2011) 1557-1565.

[7] L. Chen, Y. Gu, C. Cao, J. Zhang, J.-W. Ng, C. Tang. Performance of a submerged anaerobic membrane bioreactor with forward osmosis membrane for low-strength wastewater treatment, Water Res. 50 (2014) 114-123.

[8] N.C. Nguyen, S.S. Chen, H.T. Nguyen, H.H. Ngo, W. Guo, C.W. Hao, P.H. Lin. Applicability of a novel osmotic membrane bioreactor using a specific draw solution in wastewater treatment, Sci. Total Environ. 518-519 (2015) 586-594.

[9] R.W. Holloway, A. Achilli, T.Y. Cath. The osmotic membrane bioreactor: A critical review, Environ. Sci.: Water Res. Technol. 1 (2015) 581-605. 
[10] A.A. Alturki, J. McDonald, S.J. Khan, F.I. Hai, W.E. Price, L.D. Nghiem. Performance of a novel osmotic membrane bioreactor (OMBR) system: Flux stability and removal of trace organics, Bioresour. Technol. 113 (2012) 201-206.

[11] R.W. Holloway, J. Regnery, L.D. Nghiem, T.Y. Cath. Removal of trace organic chemicals and performance of a novel hybrid ultrafiltration-osmotic membrane bioreactor, Environ. Sci. Technol. 48 (2014) 10859-10868.

[12] W. Luo, F.I. Hai, W.E. Price, L.D. Nghiem. Water extraction from mixed liquor of an aerobic bioreactor by forward osmosis: Membrane fouling and biomass characteristics assessment, Sep. Purif. Technol. 145 (2015) 56-62.

[13] B. Mi, M. Elimelech. Organic fouling of forward osmosis membranes: Fouling reversibility and cleaning without chemical reagents, J. Membr. Sci. 348 (2010) 337-345.

[14] G.L. Qiu, Y.P. Ting. Osmotic membrane bioreactor for wastewater treatment and the effect of salt accumulation on system performance and microbial community dynamics, Bioresour. Technol. 150 (2013) 287-297.

[15] W. Luo, H.V. Phan, F.I. Hai, W.E. Price, W. Guo, H.H. Ngo, K. Yamamoto, L.D. Nghiem. Effects of salinity build-up on the performance and bacterial community structure of a membrane bioreactor, Bioresour. Technol. 200 (2016) 305-310.

[16] X.H. Wang, Y. Chen, B. Yuan, X.F. Li, Y.P. Ren. Impacts of sludge retention time on sludge characteristics and membrane fouling in a submerged osmotic membrane bioreactor, Bioresour. Technol. 161 (2014) 340-347.

[17] X.H. Wang, B. Yuan, Y. Chen, X.F. Li, Y.P. Ren. Integration of micro-filtration into osmotic membrane bioreactors to prevent salinity build-up, Bioresour. Technol. 167 (2014) 116-123.

[18] W. Luo, F.I. Hai, J. Kang, W.E. Price, L.D. Nghiem, M. Elimelech. The role of forward osmosis and microfiltration in an integrated osmotic-microfiltration membrane bioreactor system, Chemosphere 136 (2015) 125-132.

[19] K.S. Bowden, A. Achilli, A.E. Childress. Organic ionic salt draw solutions for osmotic membrane bioreactors, Bioresour. Technol. 122 (2012) 207-216.

[20] A.J. Ansari, F.I. Hai, W. Guo, H.H. Ngo, W.E. Price, L.D. Nghiem. Selection of forward osmosis draw solutes for subsequent integration with anaerobic treatment to facilitate resource recovery from wastewater, Bioresour. Technol. 191 (2015) 30-36. 
[21] N.T. Hau, S.S. Chen, N.C. Nguyen, K.Z. Huang, H.H. Ngo, W.S. Guo. Exploration of EDTA sodium salt as novel draw solution in forward osmosis process for dewatering of high nutrient sludge, J. Membr. Sci. 455 (2014) 305-311.

[22] A.A. Alturki, N. Tadkaew, J.A. McDonald, S.J. Khan, W.E. Price, L.D. Nghiem. Combining MBR and NF/RO membrane filtration for the removal of trace organics in indirect potable water reuse applications, J. Membr. Sci. 365 (2010) 206-215.

[23] N. Tadkaew, F.I. Hai, J.A. McDonald, S.J. Khan, L.D. Nghiem. Removal of trace organics by MBR treatment: The role of molecular properties, Water Res. 45 (2011) 2439-2451.

[24] T.Y. Cath, N.T. Hancock, J. Lampi, L.D. Nghiem, M. Xie, N.Y. Yip, M. Elimelech, J.R. McCutcheon, R.L. McGinnis, A. Achilli, D. Anastasio, A.R. Brady, A.E. Childress, I.V. Farr. Standard methodology for evaluating membrane performance in osmotically driven membrane processes, Desalination 312 (2013) 31-38.

[25] F.I. Hai, K. Tessmer, L.N. Nguyen, J. Kang, W.E. Price, L.D. Nghiem. Removal of micropollutants by membrane bioreactor under temperature variation, J. Membr. Sci. 383 (2011) 144-151.

[26] A. D'Haese, P. Le-Clech, S. Van Nevel, K. Verbeken, E.R. Cornelissen, S.J. Khan, A.R.D. Verliefde. Trace organic solutes in closed-loop forward osmosis applications: Influence of membrane fouling and modeling of solute build-up, Water Res. 47 (2013) $5232-5244$.

[27] X. Zhang, P.L. Bishop, B.K. Kinkle. Comparison of extraction methods for quantifying extracellular polymers in biofilms, Water Sci. Technol. 39 (1999) 211-218.

[28] O.H. Lowry, N.J. Rosebrough, A.L. Farr, R.J. Randall. Protein measurement with the Folin phenol reagent, J. Biol. Chem. 193 (1951) 265-275.

[29] M. Dubois, K.A. Gilles, J.K. Hamilton, P.A. Rebers, F. Smith. Colorimetric method for determination of sugars and related substances, Anal. Chem. 28 (1956) 350-356.

[30] F. Ye, G. Peng, Y. Li. Influences of influent carbon source on extracellular polymeric substances (EPS) and physicochemical properties of activated sludge, Chemosphere 84 (2011) 1250-1255.

[31] S. Zhao, L. Zou. Relating solution physicochemical properties to internal concentration polarization in forward osmosis, J. Membr. Sci. 379 (2011) 459-467. 
[32] Q. Li, M. Elimelech. Organic fouling and chemical cleaning of nanofiltration membranes: Measurements and mechanisms, Environ. Sci. Technol. 38 (2004) 46834693.

[33] W.S. Ang, S. Lee, M. Elimelech. Chemical and physical aspects of cleaning of organicfouled reverse osmosis membranes, J. Membr. Sci. 272 (2006) 198-210.

[34] N.T. Hancock, T.Y. Cath. Solute coupled diffusion in osmotically driven membrane processes, Environ. Sci. Technol. 43 (2009) 6769-6775.

[35] W.H. Luo, F.I. Hai, J.G. Kang, W.E. Price, W.S. Guo, H.H. Ngo, K. Yamamoto, L.D. Nghiem. Effects of salinity build-up on biomass characteristics and trace organic chemical removal: Implications on the development of high retention membrane bioreactors, Bioresour. Technol. 177 (2015) 274-281.

[36] E. Reid, X. Liu, S.J. Judd. Effect of high salinity on activated sludge characteristics and membrane permeability in an immersed membrane bioreactor, J. Membr. Sci. 283 (2006) 164-171.

[37] W.C.L. Lay, Y. Liu, A.G. Fane. Impacts of salinity on the performance of high retention membrane bioreactors for water reclamation: A review, Water Res. 44 (2010) 21-40.

[38] A. Menniti, E. Morgenroth. Mechanisms of SMP production in membrane bioreactors: Choosing an appropriate mathematical model structure, Water Res. 44 (2010) 5240-5251.

[39] M.C. Diez, D. Pouleurs, R. Navia, G. Vidal. Effect of EDTA and Fe-EDTA complex concentration on TCF Kraft mill effluent degradability. Batch and continuous treatments, Water Res. 39 (2005) 3239-3246.

[40] C. Pelletier, P. Bourlioux, J. Van Heijenoort. Effects of sub-minimal inhibitory concentrations of EDTA on growth of Escherichia coli and the release of lipopolysaccharide, FEMS Microbiol. Lett. 117 (1994) 203-206.

[41] H. Liu, H.H.P. Fang. Extraction of extracellular polymeric substances (EPS) of sludges, J. Biotechnol. 95 (2002) 249-256.

[42] C.G. van Ginkel, K.L. Vandenbroucke, C.A. Stroo. Biological removal of EDTA in conventional activated-sludge plants operated under alkaline conditions, Bioresour. Technol. 59 (1997) 151-155.

[43] R.W. Holloway, A.E. Childress, K.E. Dennett, T.Y. Cath. Forward osmosis for concentration of anaerobic digester centrate, Water Res. 41 (2007) 4005-4014. 
[44] G.J. Irvine, S. Rajesh, M. Georgiadis, W.A. Phillip. Ion selective permeation through cellulose acetate membranes in forward osmosis, Environ. Sci. Technol. 47 (2013) 1374513753.

[45] L. Ye, M.-F. Shao, T. Zhang, A.H.Y. Tong, S. Lok. Analysis of the bacterial community in a laboratory-scale nitrification reactor and a wastewater treatment plant by 454pyrosequencing, Water Res. 45 (2011) 4390-4398.

[46] A. Uygur, F. Karg1. Salt inhibition on biological nutrient removal from saline wastewater in a sequencing batch reactor, Enzyme Microb. Technol. 34 (2004) 313-318.

[47] Z. Hu, K. Chandran, D. Grasso, F.B. Smets. Nitrification inhibition by ethylenediaminebased chelating agents, Environ. Eng. Sci. 20 (2003) 219-228.

[48] M.F.R. Zuthi, W.S. Guo, H.H. Ngo, L.D. Nghiem, F.I. Hai. Enhanced biological phosphorus removal and its modeling for the activated sludge and membrane bioreactor processes, Bioresour. Technol. 139 (2013) 363-374.

[49] W.J. Yap, J. Zhang, W.C.L. Lay, B. Cao, A.G. Fane, Y. Liu. State of the art of osmotic membrane bioreactors for water reclamation, Bioresour. Technol. 122 (2012) 217-222.

[50] D.L. Shaffer, N.Y. Yip, J. Gilron, M. Elimelech. Seawater desalination for agriculture by integrated forward and reverse osmosis: Improved product water quality for potentially less energy, J. Membr. Sci. 415-416 (2012) 1-8.

[51] W. Luo, F.I. Hai, W.E. Price, W. Guo, H.H. Ngo, K. Yamamoto, L.D. Nghiem. Phosphorus and water recovery by a novel osmotic membrane bioreactor-reverse osmosis system, Bioresour. Technol. 200 (2016) 297-304.

[52] M. Xie, L.D. Nghiem, W.E. Price, M. Elimelech. A forward osmosis-membrane distillation hybrid process for direct sewer mining: System performance and limitations, Environ. Sci. Technol. 47 (2013) 13486-13493.

[53] K.C. Wijekoon, F.I. Hai, J. Kang, W.E. Price, W. Guo, H.H. Ngo, L.D. Nghiem. The fate of pharmaceuticals, steroid hormones, phytoestrogens, UV-filters and pesticides during MBR treatment, Bioresour. Technol. 144 (2013) 247-254. 


\section{LIST OF FIGURES}

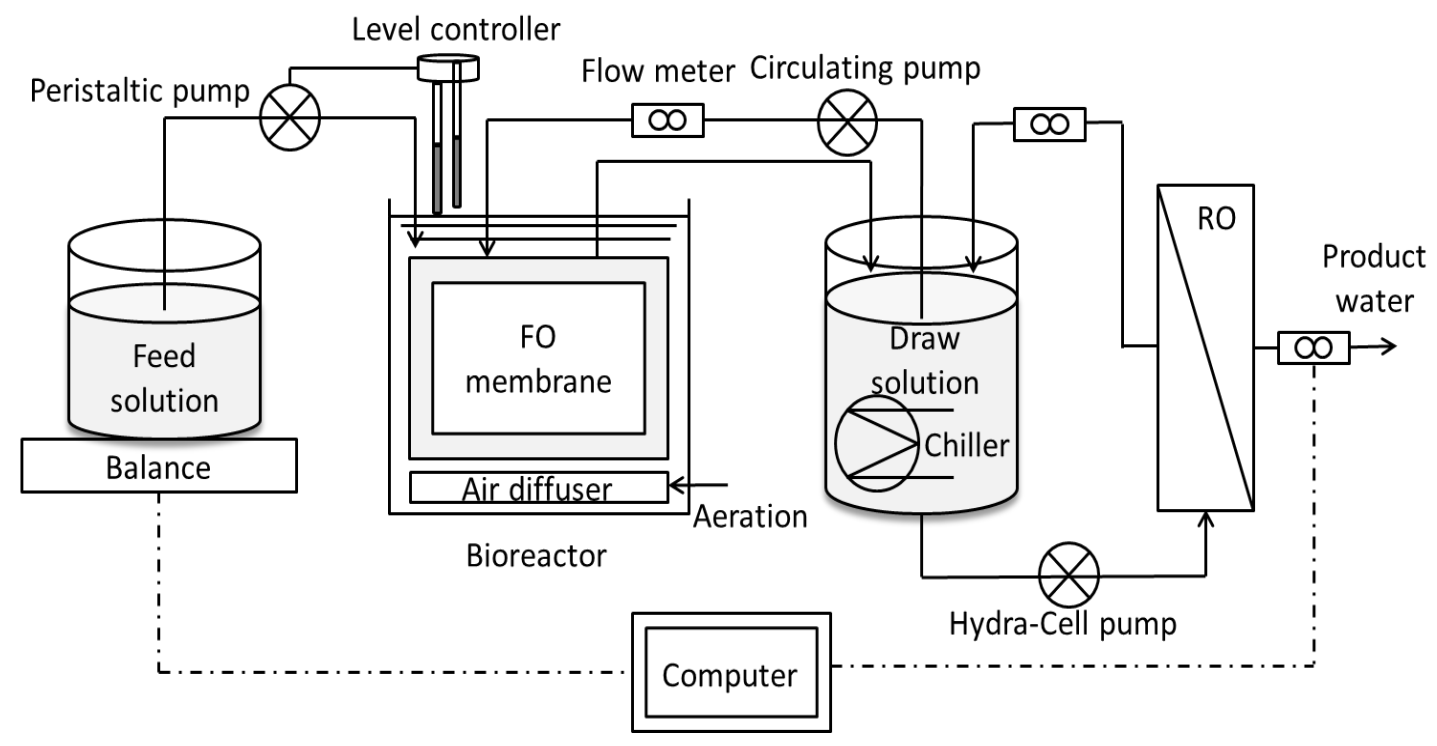

Figure 1: Schematic diagram of a bench-scale OMBR-RO system. 


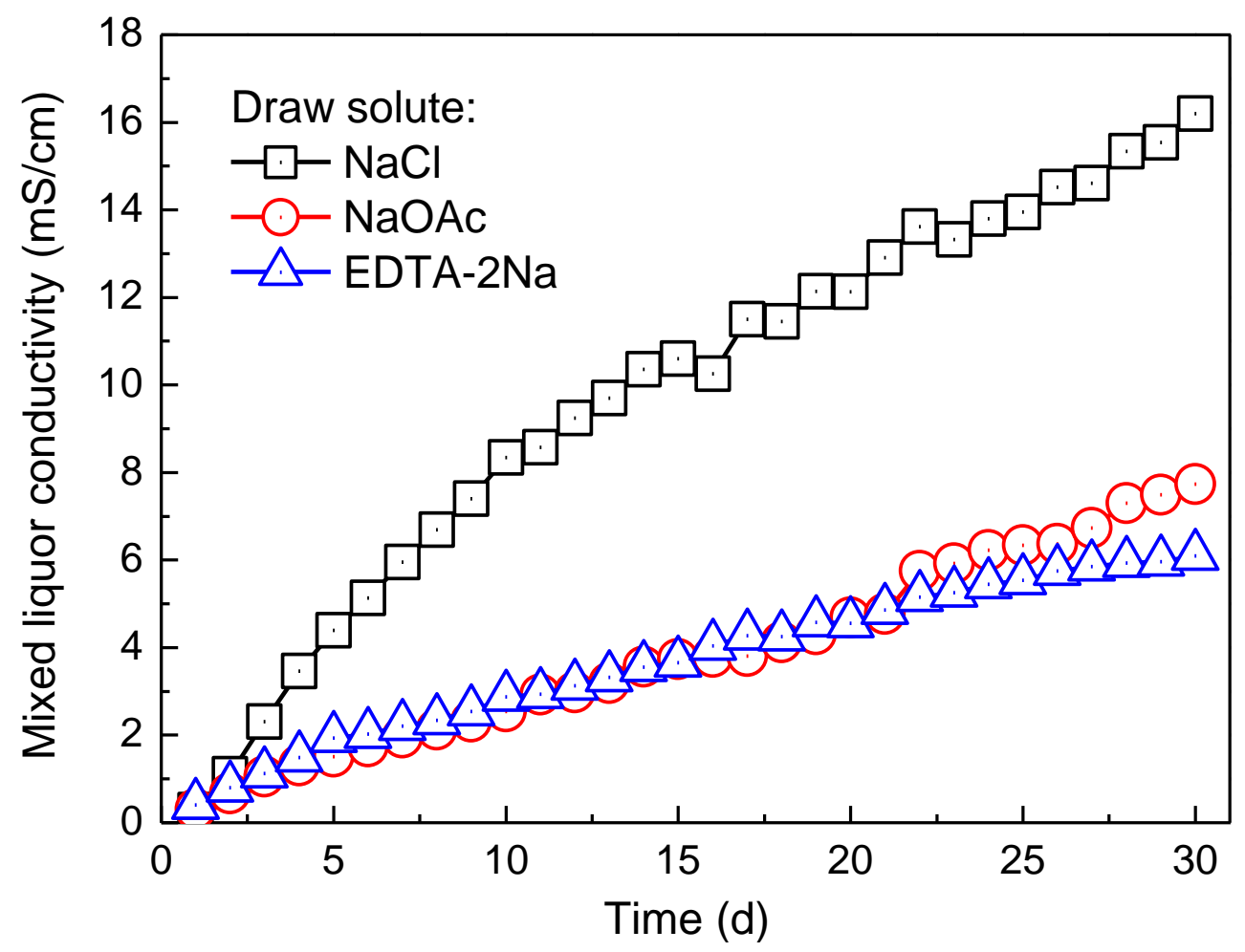

Figure 2: Mixed liquor electrical conductivity during OMBR operation with each draw solute. Experimental conditions: draw solution $=0.5 \mathrm{M} \mathrm{NaCl}, 0.6 \mathrm{M} \mathrm{NaOAc}$, or $0.3 \mathrm{M}$ EDTA-2Na (generating 23 bar osmotic pressure); cross-flow velocity $=2.8 \mathrm{~cm} / \mathrm{s} ;$ DO $=5$ $\mathrm{mg} / \mathrm{L}$; initial MLSS $=5 \mathrm{~g} / \mathrm{L}$; initial HRT $=33-43 \mathrm{~h}$; temperature $=22 \pm 1{ }^{\circ} \mathrm{C}$.

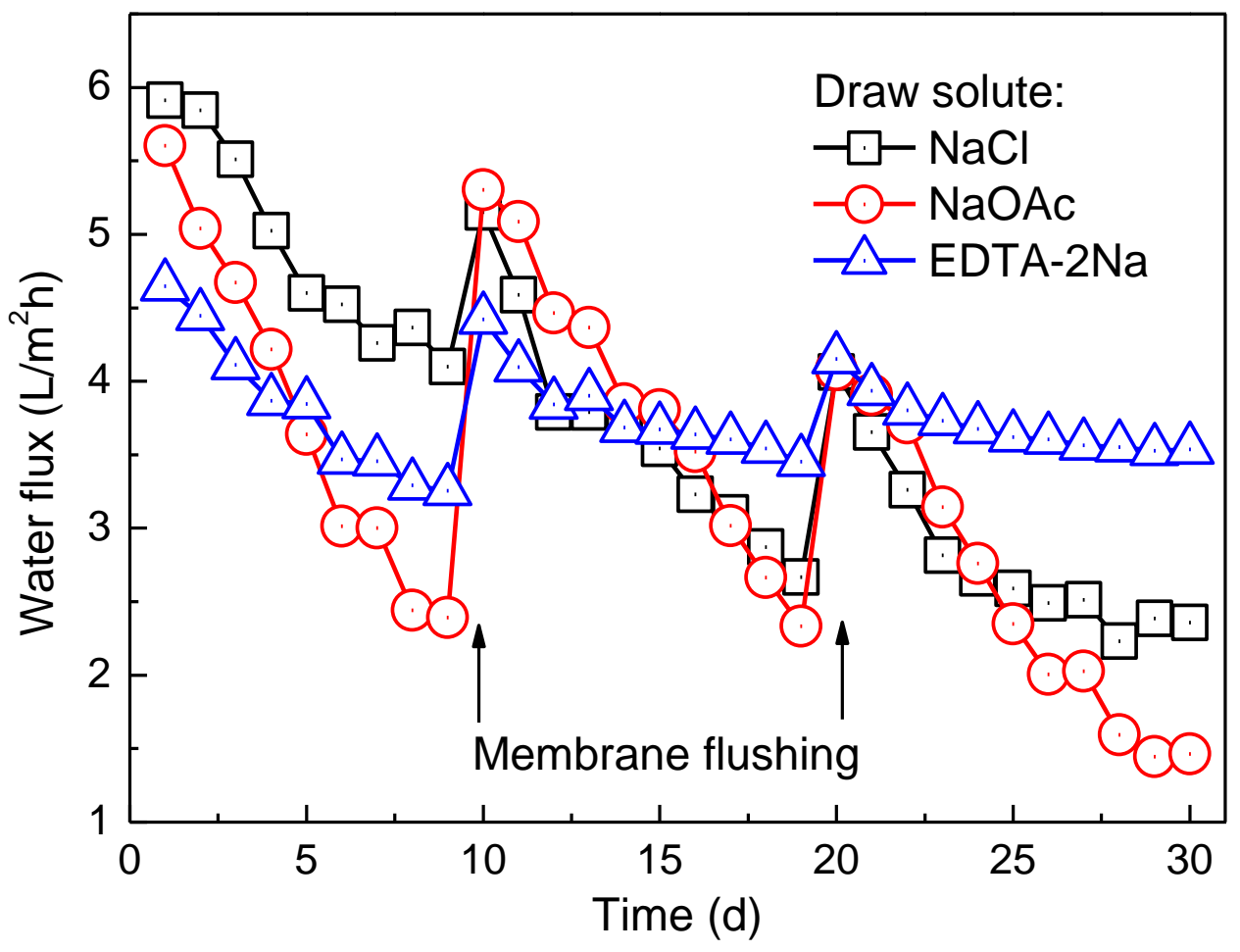


Figure 3: Water flux of the OMBR with each draw solute. Membrane surface was physically flushed with deionized water on day 10 and 20 in each draw solute experiment. Experimental conditions are as described in the caption of Figure 2.

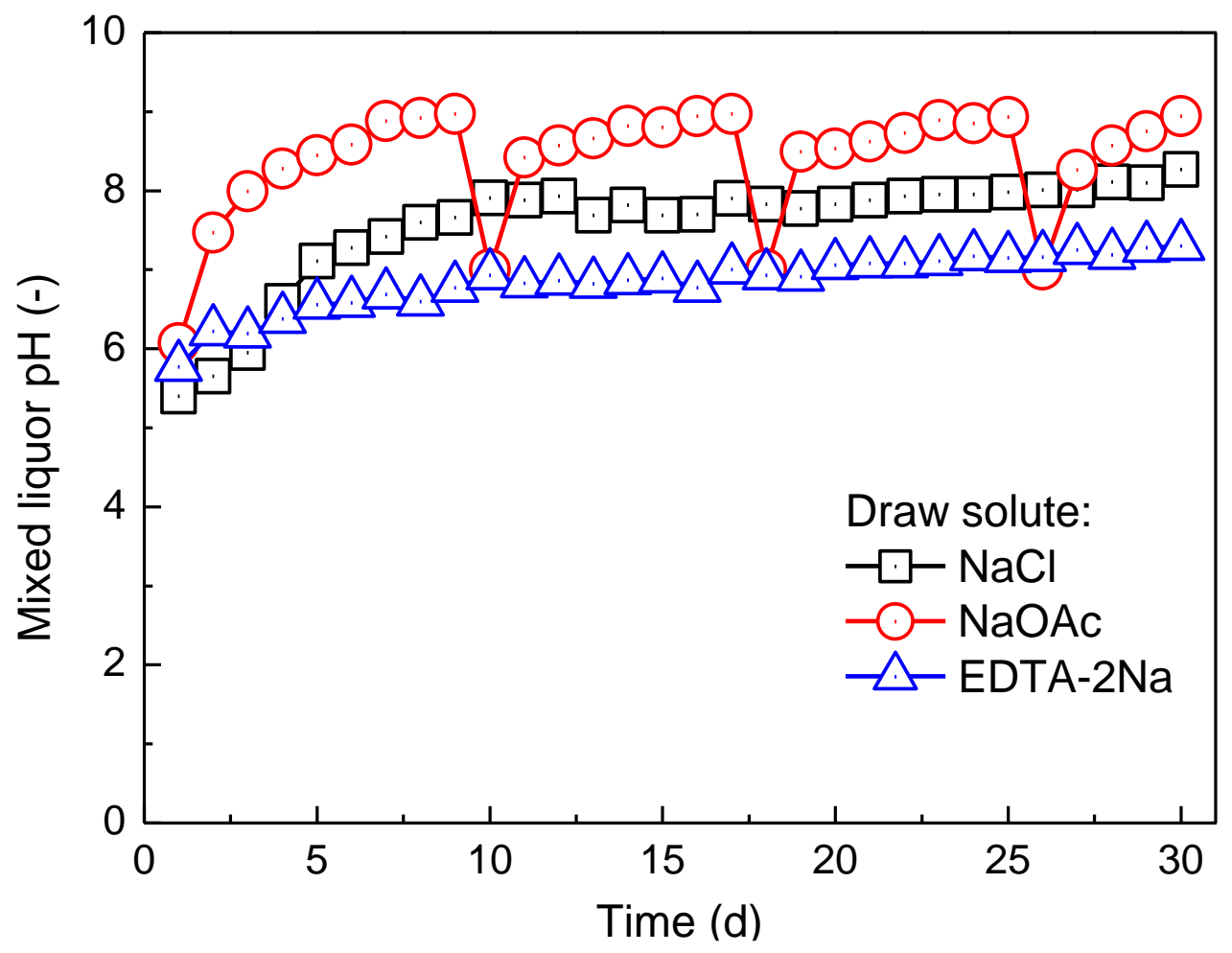

Figure 4: Mixed liquor $\mathrm{pH}$ during OMBR operation with each draw solute. The mixed liquor $\mathrm{pH}$ was reduced to $\mathrm{pH} 7$ once it increased to $\mathrm{pH} 9$ by adding a certain amount of concentrated $\mathrm{HCl}$ solution when $\mathrm{NaOAc}$ was used as the OMBR draw solute. No $\mathrm{pH}$ adjustment to the mixed liquor was applied with other two draw solutes. Experimental conditions are as described in the caption of Figure 2. 
Draw solute: $\square \mathrm{NaCl} \bigcirc \mathrm{NaOAc} \triangle$ EDTA-2Na
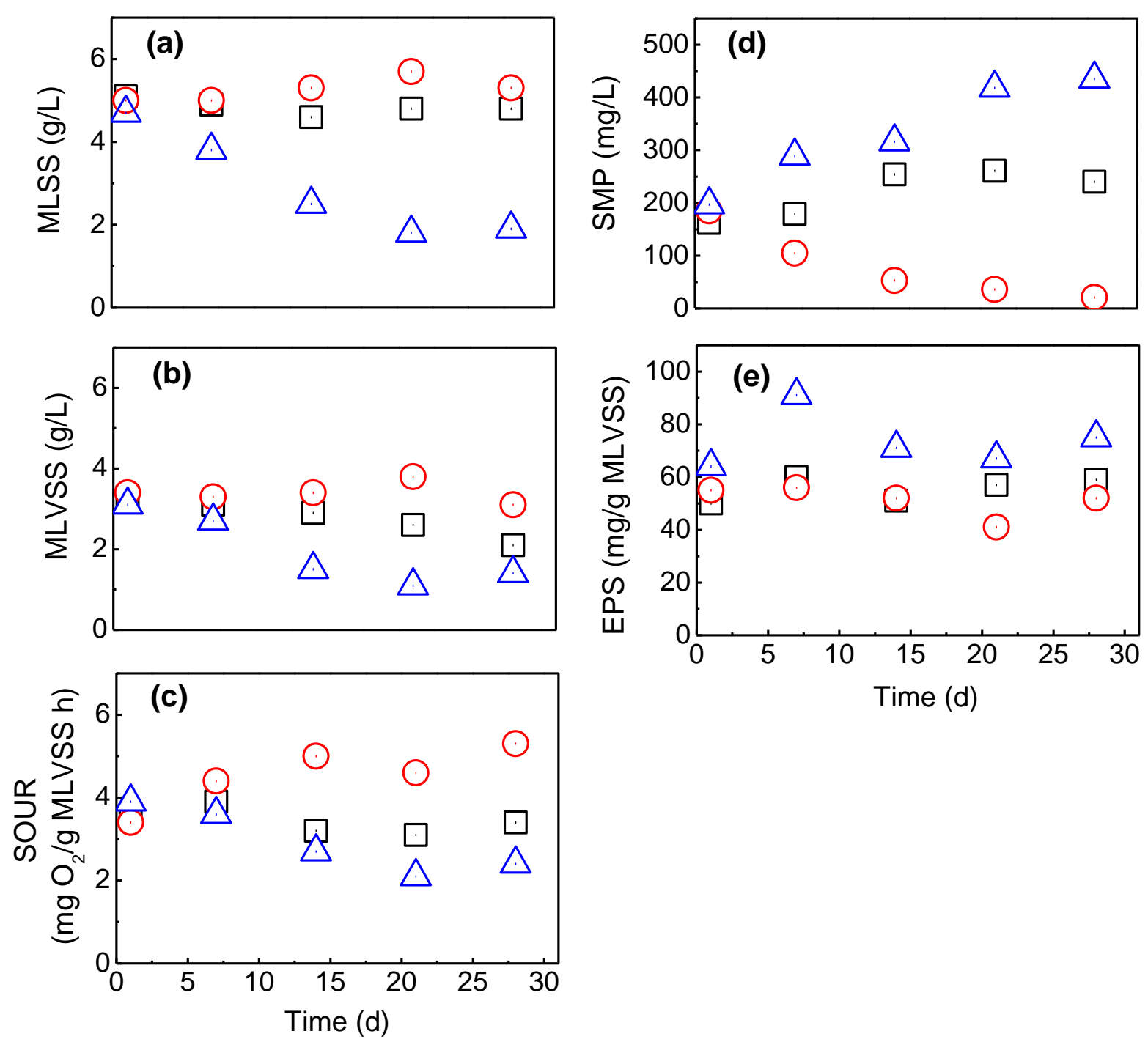

Figure 5: Key biomass characteristics during OMBR operation with each draw solute. Experimental conditions are as described in the caption of Figure 2. 


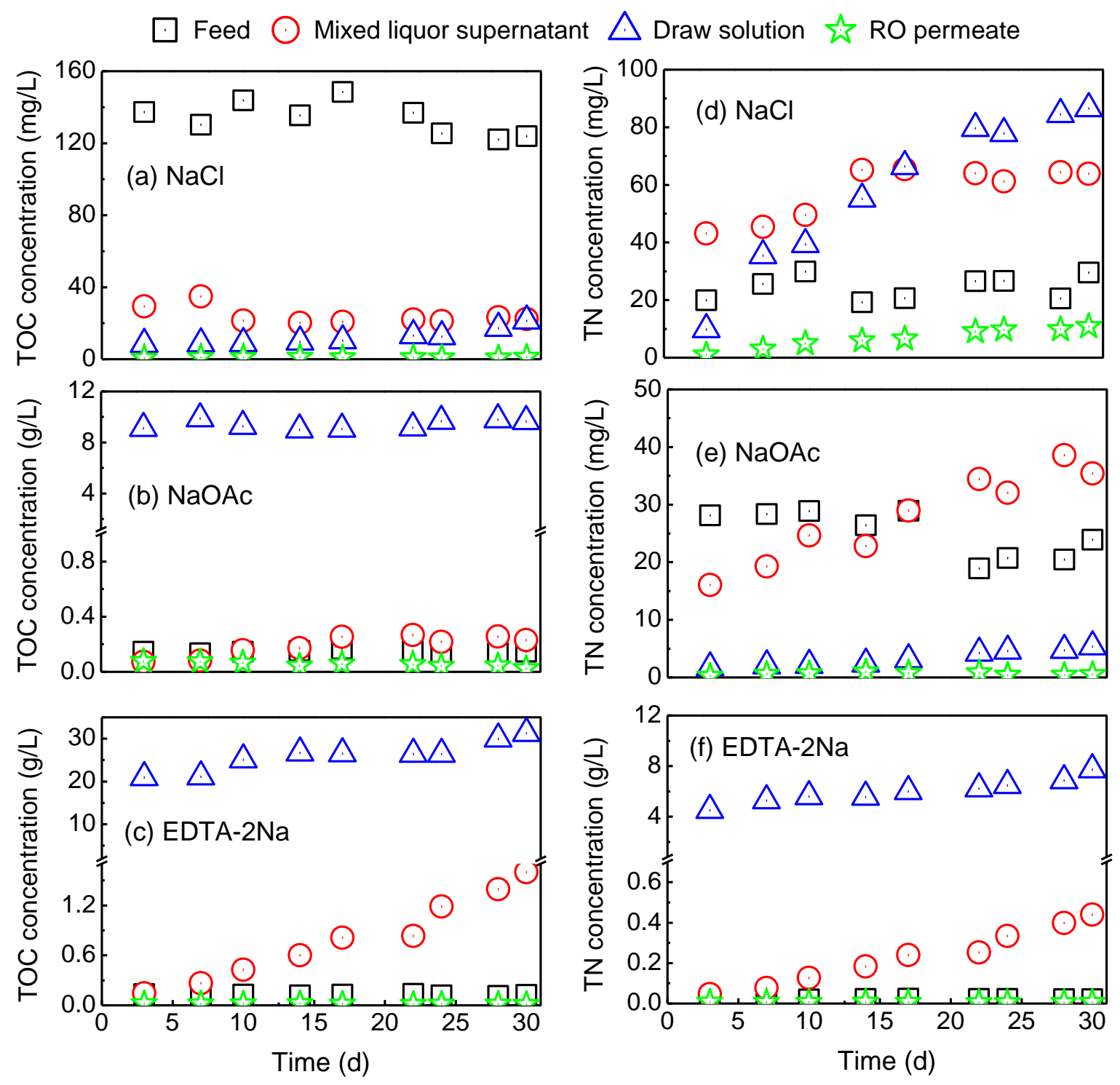

Figure 6: $\mathrm{TOC}$ and $\mathrm{TN}$ concentrations in the OMBR-RO hybrid system with each draw solute (i.e. $\mathrm{NaCl}, \mathrm{NaOAc}$, or EDTA-2Na). Experimental conditions are given in the caption of Figure 2. 


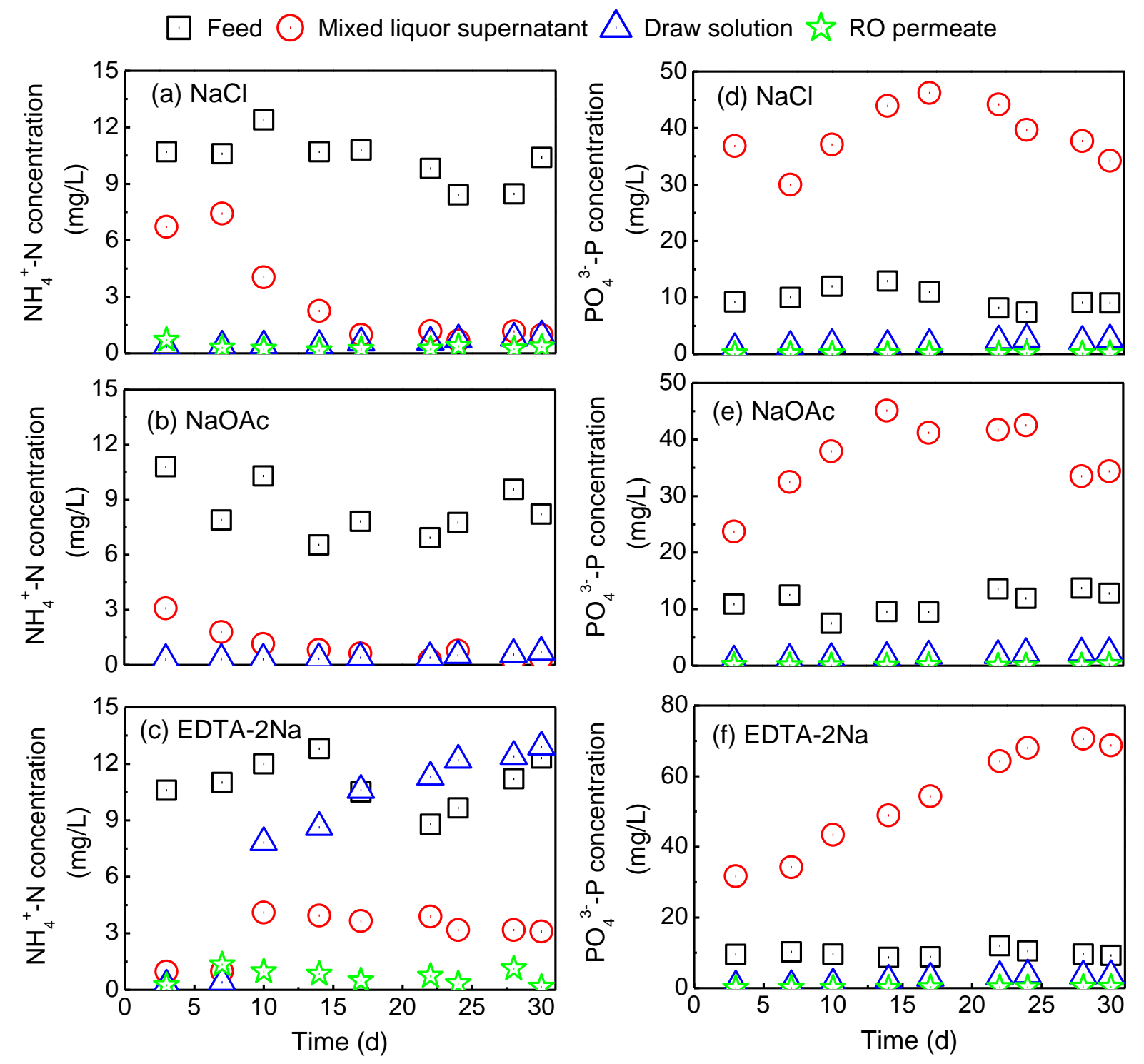

Figure 7: $\mathrm{NH}_{4}{ }^{+}-\mathrm{N}$ and $\mathrm{PO}_{4}{ }^{3-}-\mathrm{P}$ concentrations in the OMBR-RO hybrid system with each draw solute (i.e. $\mathrm{NaCl}, \mathrm{NaOAc}$, or EDTA-2Na). Experimental conditions are detailed in the caption of Figure 2. 


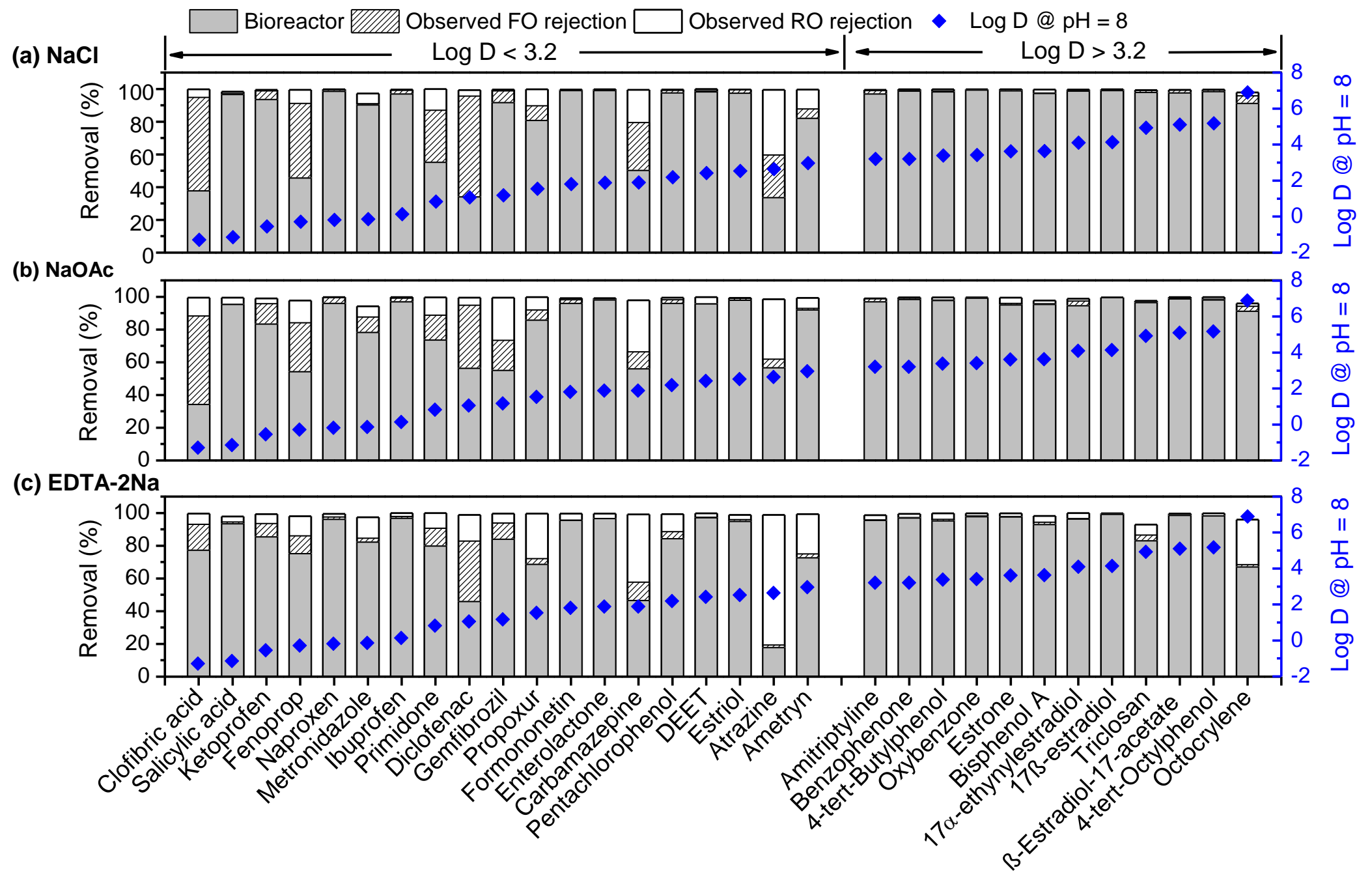


Figure 8: Removal of TrOCs in the OMBR-RO hybrid system with each draw solute (i.e. NaCl, NaOAc, or EDTA-2Na). TrOCs were ordered according to their hydrophobicity determined by their effective octanol-water partition coefficient $(\log \mathrm{D})$ at $\mathrm{pH}$ 8. Experimental conditions are summarized in the caption of Figure 2. 
1 LIST OF TABLES

2 Table 1: Reverse salt flux of each draw solution at a concentration to produce an osmotic

3 pressure of 23 bar (average \pm standard deviation of duplicate measurements)

\begin{tabular}{cccc}
\hline Draw solution & $\begin{array}{c}\text { Diffusion coefficient } \\
\left(\mathrm{m}^{2} / \mathrm{s}\right)^{*}\end{array}$ & $\begin{array}{c}\text { Solute molecular } \\
\text { weight }(\mathrm{g} / \mathrm{mol})\end{array}$ & $\begin{array}{c}\text { Reverse solute } \\
\text { flux }\left(\mathrm{mmol} / \mathrm{m}^{2} \mathrm{~h}\right)\end{array}$ \\
\hline $0.5 \mathrm{M} \mathrm{NaCl}$ & $1.47 \times 10^{-9}$ & 58.44 & $123 \pm 3$ \\
$0.6 \mathrm{M} \mathrm{NaOAc}$ & $1.44 \times 10^{-9}$ & 82.03 & $59 \pm 7$ \\
$0.3 \mathrm{M}$ EDTA-2Na & $5.83 \times 10^{-10}$ & 336.24 & $5 \pm 1$ \\
\hline
\end{tabular}

4 *Data from Ansari et al. [20].

5

6

7

8

9

10

11

12 bioreactors for water reuse 
Wenhai Luo a , Faisal I. Hai ${ }^{\text {a }}$, William E. Price ${ }^{\mathrm{b}}$, Menachem Elimelech ${ }^{\mathrm{c}}$, and Long D.

19 a Strategic Water Infrastructure Laboratory, School of Civil, Mining and Environmental Engineering, University of Wollongong, Wollongong, NSW 2522, Australia

21 b Strategic Water Infrastructure Laboratory, School of Chemistry, University of Wollongong,

${ }^{\mathrm{c}}$ Department of Chemical and Environmental Engineering, Yale University, New Haven, Connecticut 06520-8286, United States

*Corresponding author: longn@uow.edu.au; Ph: +61 (2) 42214590. 
Table S1: Physicochemical properties of the selected 31 trace organic contaminants.

\begin{tabular}{|c|c|c|c|c|}
\hline Compounds & $\begin{array}{l}\text { Chemical } \\
\text { formula }\end{array}$ & $\begin{array}{c}\log \mathrm{D} \\
\text { at } \mathrm{pH}=8\end{array}$ & $\begin{array}{c}\text { MW } \\
(\mathrm{g} / \mathrm{mol})\end{array}$ & Chemical structure \\
\hline Clofibric acid & $\mathrm{C}_{10} \mathrm{H}_{11} \mathrm{ClO}_{3}$ & -1.29 & 214.6 & \\
\hline Salicylic acid & $\mathrm{C}_{7} \mathrm{H}_{6} \mathrm{O}_{3}$ & -1.14 & 138.1 & \\
\hline Ketoprofen & $\mathrm{C}_{16} \mathrm{H}_{14} \mathrm{O}_{3}$ & -0.55 & 254.3 & \\
\hline Fenoprop & $\mathrm{C}_{9} \mathrm{H}_{7} \mathrm{Cl}_{3} \mathrm{O}_{3}$ & -0.28 & 269.5 & \\
\hline Naproxen & $\mathrm{C}_{14} \mathrm{H}_{14} \mathrm{O}_{3}$ & -0.18 & 230.3 & \\
\hline Metronidazole & $\mathrm{C}_{6} \mathrm{H}_{9} \mathrm{~N}_{3} \mathrm{O}_{3}$ & -0.14 & 171.2 & \\
\hline Ibuprofen & $\mathrm{C}_{13} \mathrm{H}_{18} \mathrm{O}_{2}$ & 0.14 & 206.3 & \\
\hline Primidone & $\mathrm{C}_{12} \mathrm{H}_{14} \mathrm{~N}_{2} \mathrm{O}_{2}$ & 0.83 & 218.3 & \\
\hline Diclofenac & $\mathrm{C}_{14} \mathrm{H}_{11} \mathrm{Cl}_{2} \mathrm{NO}_{2}$ & 1.06 & 296.2 & \\
\hline Gemfibrozil & $\mathrm{C}_{15} \mathrm{H}_{22} \mathrm{O}_{3}$ & 1.18 & 250.3 & \\
\hline Propoxur & $\mathrm{C}_{11} \mathrm{H}_{15} \mathrm{NO}_{3}$ & 1.54 & 209.2 & \\
\hline Formononetin & $\mathrm{C}_{16} \mathrm{H}_{12} \mathrm{O}_{4}$ & 1.81 & 268.3 & \\
\hline Enterolactone & $\mathrm{C}_{18} \mathrm{H}_{18} \mathrm{O}_{4}$ & 1.88 & 298.33 & \\
\hline Carbamazepine & $\mathrm{C}_{15} \mathrm{H}_{12} \mathrm{~N}_{2} \mathrm{O}$ & 1.89 & 236.3 & \\
\hline Pentachlorophenol & $\mathrm{C}_{6} \mathrm{HCl}_{5} \mathrm{O}$ & 2.19 & 266.4 & \\
\hline DEET & $\mathrm{C}_{12} \mathrm{H}_{17} \mathrm{NO}$ & 2.42 & 191.3 & \\
\hline
\end{tabular}




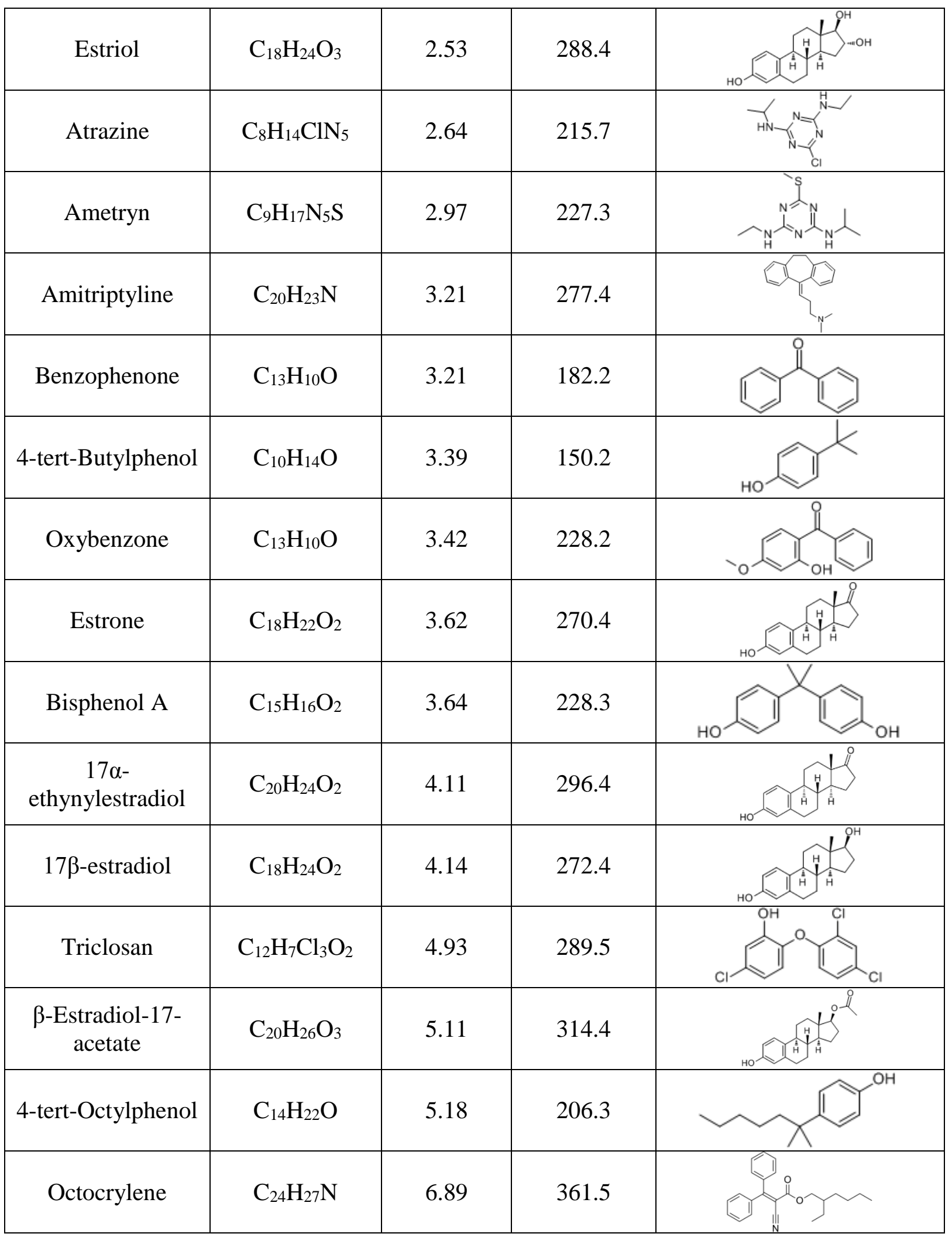

24 Source: SciFinder Scholar (ACS) database. 
27 Table S2: Polysaccharide and protein contents in the fouling layer on the FO membrane 28 surface during OMBR operation with each draw solution.

\begin{tabular}{|c|c|c|c|c|}
\hline \multirow{2}{*}{ Draw solution } & \multicolumn{2}{|c|}{ Day 10 } & \multicolumn{2}{c|}{ Day 20 } \\
\cline { 2 - 5 } & $\begin{array}{c}\text { Polysaccharide } \\
\left(\mathrm{mg} / \mathrm{m}^{2}\right)\end{array}$ & $\begin{array}{c}\text { Protein } \\
\left(\mathrm{mg} / \mathrm{m}^{2}\right)\end{array}$ & $\begin{array}{c}\text { Polysaccharide } \\
\left(\mathrm{mg} / \mathrm{m}^{2}\right)\end{array}$ & $\begin{array}{c}\text { Protein } \\
\left(\mathrm{mg} / \mathrm{m}^{2}\right)\end{array}$ \\
\hline $0.5 \mathrm{M} \mathrm{NaCl}$ & 158 & 236 & 109 & 186 \\
\hline $0.6 \mathrm{M} \mathrm{NaOAc}$ & 372 & 820 & 316 & 760 \\
\hline $0.3 \mathrm{M}$ EDTA-2Na & 89 & 195 & 19 & 52 \\
\hline
\end{tabular}




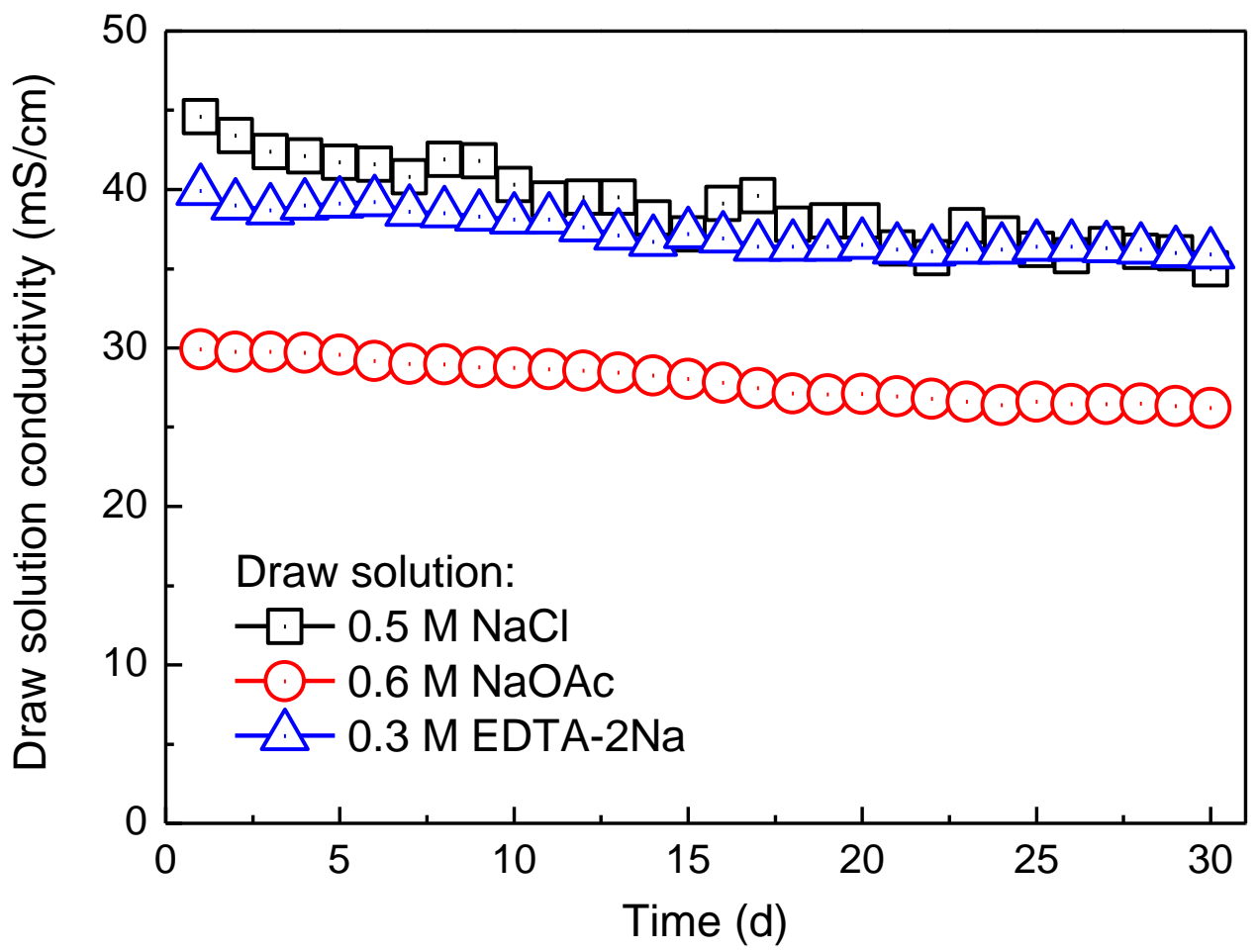

30 Figure S1: Draw solution electrical conductivity during each OMBR-RO operation. The RO 31 permeate flux was adjusted daily to meet that of OMBR by changing the applied hydraulic 32 pressure while maintaining the constant cross-flow velocity of $41.7 \mathrm{~cm} / \mathrm{s}$. Experimental 33 conditions: FO mode; draw solution osmotic pressure $=23$ bar; cross-flow velocity $=2.8$ $34 \mathrm{~cm} / \mathrm{s} ; \mathrm{DO}=5 \mathrm{mg} / \mathrm{L} ;$ initial MLSS $=5 \mathrm{~g} / \mathrm{L} ;$ initial HRT $=33-43 \mathrm{~h}$; temperature $=22 \pm 1{ }^{\circ} \mathrm{C}$. 


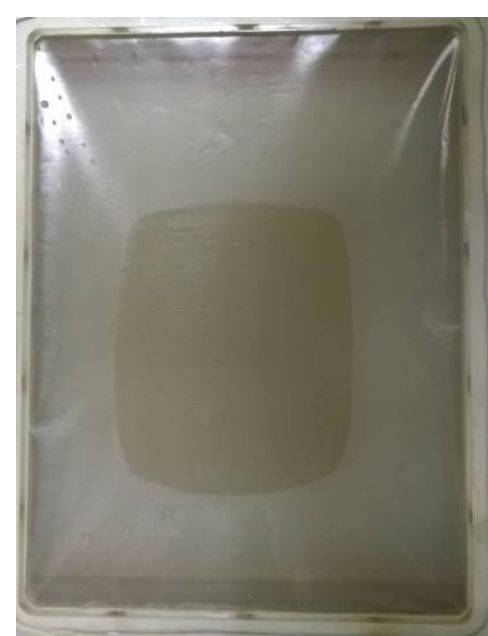

New membrane

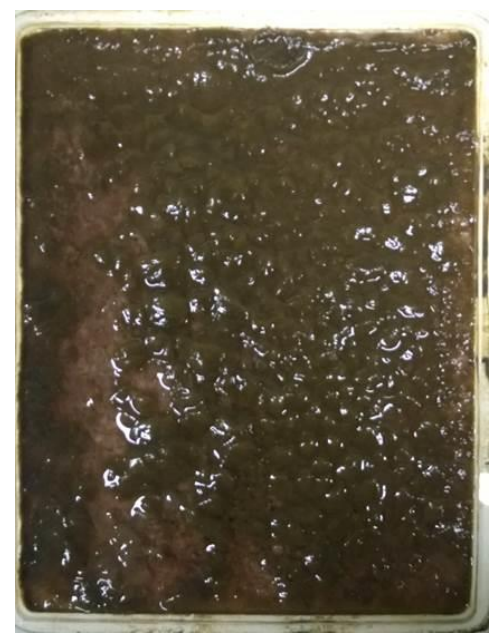

Operation with $\mathrm{NaOAc}$

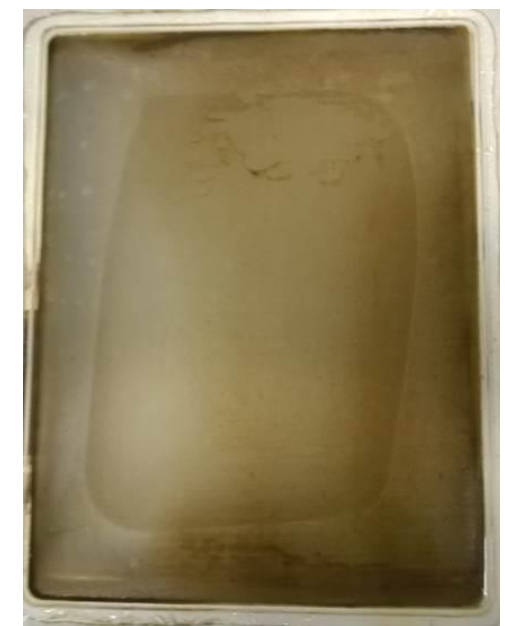

Operation with $\mathrm{NaCl}$

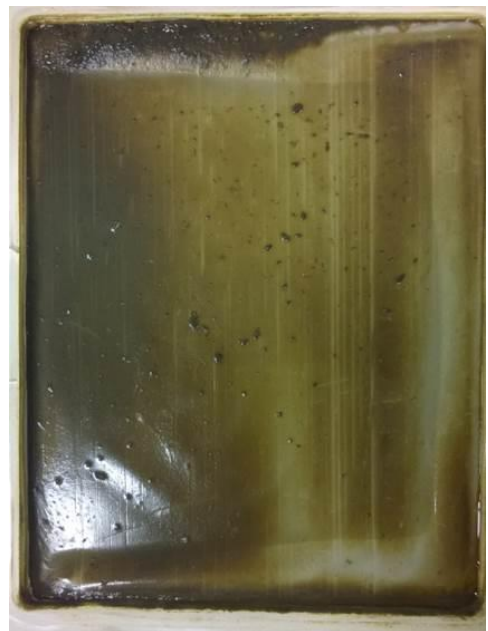

Operation with EDTA-2Na

Figure S2: Visual observation of the FO membrane surface at the conclusion of OMBR operation with each draw solute. Membrane surface was physically flushed with deionized water on day 10 and 20. Experimental conditions are as described in the caption of Figure S1.

\section{RESEARCH HIGHLIGHT}

- Ionic organic draw solutes could be used to mitigate salinity build-up in OMBR

- $\mathrm{NaOAc}$ and EDTA-2Na produced lower water and reverse salt fluxes than $\mathrm{NaCl}$

- EDTA-2Na resulted in less membrane fouling than both $\mathrm{NaCl}$ and $\mathrm{NaOAc}$

- OMBR-RO could remove TrOCs by over $97 \%$ regardless of the draw solutes 
